\title{
Clinical Utility of the PFA-100
}

\author{
Emmanuel J. Favaloro, Ph.D., M.A.I.M.S. ${ }^{1}$
}

\section{ABSTRACT}

The PFA-100 (platelet function analyzer) is a relatively new tool for the investigation of primary hemostasis. This article reviews the history of the PFA-100 and details its clinical utility in several settings. The PFA-100 was first introduced to us in 1995 in an issue of Seminars in Thrombosis and Hemostasis, which included data from a field trial headed by Dr. Eberhard Mammen. Since that time, the PFA-100 has featured in nearly 500 publications and some 35 reviews. The PFA-100 has potential utility in monitoring antiplatelet therapy (including aspirin) and as a screening tool for investigating possible von Willebrand disease (VWD) and various platelet disorders. The PFA-100 also has potential value for monitoring DDAVP (desmopressin) therapy in both VWD and functional platelet disorders. Most recent attention has focused on sensitivity to antiplatelet medication, where a new language has also emerged, with researchers talking about "aspirin resistance," "aspirin responsiveness," and "aspirin nonresponsiveness." Ultimately, the greatest strengths of the PFA-100 are its simplicity in use and excellent sensitivity to various hemostatic disturbances. However, because it is a "global" test system for primary hemostasis, this also creates a significant limitation because the PFA-100 is not specific for, nor predictive of, any particular disorder. However, used appropriately, the PFA-100 can be considered a worthwhile addition to hemostasis laboratories involved in the identification or therapeutic monitoring of primary hemostatic disorders. The potential future applications for this simple instrument are also briefly assessed.

KEYWORDS: PFA-100, primary hemostasis, aspirin, VWD, von Willebrand disease

The PFA-100 (platelet function analyzer) is a whole blood platelet-function screening tool. It was developed from an instrument called the Thrombostat 4000 (von der Goltz, Seeon, Germany), ${ }^{1}$ and news of its release to the broader hemostasis community was first relayed in a special supplement of Seminars in Thrombosis and Hemostasis in 1995.,3 Indeed, all the articles within that particular issue of Seminars in Thrombosis and Hemostasis pertained to either the Thrombostat 4000 (first 16 articles) or to the PFA-100 itself (last two articles). One of the PFA-100 reports was by Kundu et $\mathrm{al}^{2}$ and derived from the manufacturer, Dade-Behring
(Marburg, Germany). This report contained a comprehensive description of the instrument, including the twocartridge test system, the mechanics involved, and some preliminary test data. In the original words of Kundu et $\mathrm{al}^{2}$ the system involved aspiration of a "blood sample under constant vacuum from the sample reservoir through a capillary and a microscopic aperture cut into the membrane. The membrane is coated with collagen and epinephrine or adenosine $5^{\prime}$-diphosphate. The presence of these biochemical stimuli, and the high shear rates generated under the standardized flow conditions, result in platelet attachment, activation, and aggregation,
${ }^{1}$ Department of Haematology, Institute of Clinical Pathology and Medical Research (ICPMR), Westmead Hospital, NSW, Australia. Address for correspondence and reprint requests: Emmanuel J. Favaloro, Ph.D., M.A.I.M.S., Department of Haematology, Institute of Clinical Pathology and Medical Research (ICPMR), SWAHS, Westmead, NSW, 2145, Australia (e-mail: emmanuel.favaloro@swahs. health.nsw.gov.au).
A Tribute to Eberhard F. Mammen, M.D. (1930-2008); Guest Editor, Emmanuel J. Favaloro, Ph.D., M.A.I.M.S.

Semin Thromb Hemost 2008;34:709-733. Copyright (C) 2008 by Thieme Medical Publishers, Inc., 333 Seventh Avenue, New York, NY 10001, USA. Tel: +1(212) 584-4662.

DOI 10.1055/s-0029-1145254. ISSN 0094-6176. 
slowly building a stable platelet plug at the aperture. The time required to obtain full occlusion of the aperture is reported as the 'closure time.' We have found that impairment of von Willebrand factor, or inhibition of platelet receptors glycoprotein Ib or IIb/IIIa with monoclonal antibodies or peptides, resulted in abnormal closure times. An antifibrinogen antibody, in contrast, failed to show any effect. The test appears to be sensitive to platelet adherence and aggregation abnormalities. The PFA-100 system has potential applications in routine evaluation of platelet function in the clinical setting because of its accuracy, ease of operation, and rapid turnaround of results."

The second PFA-100 report was from Mammen and colleagues, ${ }^{3}$ who described the findings of a "fieldtrial" of the PFA-100 to assess performance characteristics. They assessed both "healthy subjects (normals) who had not ingested any medications, and patients (abnormals) with primary, platelet-related hemostasis defects, which included users of aspirin." Tests were performed with both test cartridges (i.e., collagen/adenosine diphosphate [C/ADP] and collagen/epinephrine $[\mathrm{C} / \mathrm{Epi}])$. The study assessed that variables such as blood drawn into either $3.8 \%$ or $3.2 \%$ sodium citrate in vacuum collection tubes (rather than syringes) could be used for testing, confirmed the need to maintain blood at room temperature, and validated manufacturer recommendations to perform tests within a 5-hour time span after collection. Normal reference values for closure times (CTs) obtained in the field trial were 77 to 133 seconds for C/ADP and 98 to 185 seconds for $\mathrm{C} /$ Epi. Interestingly, these ranges were similar to those determined by Kundu et $\mathrm{al}^{2}$ ( 63 to 123 seconds and 97 to 188 seconds, respectively) and still closely align with those currently reported in the test cartridge product insert (71 to 118 seconds and 85 to 165 seconds, respectively). These ranges are also similar to those in use in our laboratory (67 to 127 seconds and 94 to 162 seconds, respectively), but some variation in normal reference values has been reported within the literature as identified later. Precision testing revealed a coefficient of derivation $(\mathrm{CV})$ of $<10 \%$ for within-day and between-day (5 days) analyses using $\mathrm{C} / \mathrm{ADP}$ cartridges and 5 to $14 \%$ for both using C/Epi cartridges. This particular finding may have overestimated test precision (or reproducibility) according to subsequent studies. The abstract from Mammen et $\mathrm{al}^{3}$ simply concluded with "No clinically important differences were found between measurements in the two positions of the instrument, although one follows the other." Tests were also performed on 99 normal individuals and 70 "abnormal individuals" to derive receiver/operator characteristics (ROC) curves that help assess combined sensitivity and specificity. Derived values were defined as 0.76 for $\mathrm{C} / \mathrm{ADP}$ and 0.89 for $\mathrm{C} / \mathrm{Epi}$, which compared well with the value of 0.70 obtained for the Ivy bleeding time. A value of 1.0 means that the test has "identified all normals and abnormals accurately," whereas a value of 0.5 indicates that a test is noninformative. Aspirin sensitivity was also assessed using 24 patients; 20 had an abnormal C/Epi CT and normal C/ADP CT (this pattern represents the now well-recognized or "classic" aspirin test blueprint), three had abnormal C/Epi and C/ ADP CTs, and one had normal CTs for both cartridges. In retrospect, the last case appears to be one of the first "aspirin-resistant" cases identified by the PFA- 100 .

There was only one publication on the PFA-100 in $1996,{ }^{4}$ and two articles appeared in $1997 .{ }^{5,6}$ Two of these articles were again from the manufacturer ${ }^{4,5}$ and included most of the authors of the original descriptive article. ${ }^{2}$ The 1996 article once again described the PFA-100, and the subsequent 1997 article reported a comparison of four common commercial citrate bloodcollection systems, simply confirming that different commercial systems could be used with high comparative findings, important within the context of multiple test users. The other PFA-100 article published in 1997 concerned the effects of aspirin on healthy individuals as detected by platelet aggregation, the PFA-100, and by the skin bleeding time (SBT; measured using the Simplate method). ${ }^{6}$ This report provided a taste of what was to come with regard to "aspirin and the PFA-100." The study used a randomized, doubleblind, placebo-controlled crossover design, with each volunteer taking placebo or (a rather high dose [750 mg] of) aspirin, 3 times a day for 5 days, with an 18-day washout period between treatments. SBTs and CTs were measured before the first dose and 0.5 hour after the last dose as well as 2 weeks after the last day of the trial. Aspirin treatment caused an increase in both the SBT (61\%) and the CT (79\%) when compared with the effects of placebo. Although the platelet aggregation response to arachidonic acid was completely inhibited by aspirin (and unaffected by placebo), the SBT was unaltered in 1 of 12 volunteers by aspirin and was significantly prolonged in 3 of the 12 volunteers during placebo treatment. The PFA-100 CT did better but was still unaltered in 1 of the 12 volunteers by aspirin and was prolonged in 1 subject during placebo treatment. The authors concluded that the PFA-100 CT was as sensitive and reproducible to the effects of aspirin on platelet function as the SBT but also produced less variable effects with fewer false-positive results. We might again note that 1 of 12 individuals in this study appeared "resistant" to aspirin therapy when assessed by the PFA- 100 .

The year 1998 was perhaps a turning point in the PFA-100 story and heralded the publication of nine articles related to this platelet function analyzer. These reports included a seminal article in the journal Blood by the French group of Fressinaud et al, ${ }^{7}$ who described test findings in 60 cases of von Willebrand disease (VWD), 
14 cases of hemophilia, 15 patients with platelet disorders, and 96 normal subjects. The report also included data on DDAVP (desmopressin) and factor concentrate therapy in these patients. The PFA-100 was found to be more sensitive to VWD than was the SBT, both to the detection of VWD and in regard to its therapeutic monitoring. Another article from that year came from Mammen et al, ${ }^{8}$ who described a multicenter trial that captured 206 healthy subjects and 176 individuals with VWD and other platelet-related defects, including 127 aspirin users. The PFA-100 was compared with classic platelet aggregometry to respectively yield comparative clinical sensitivities of $94.9 \%$ versus $94.3 \%$ and specificities of $88.8 \%$ versus $88.3 \%$. The year 1998 also saw publication of three reports describing the use of the PFA-100 in the pediatric population, ${ }^{9-11}$ one report of its use in pregnant women, ${ }^{12}$ the first report of its use in a non-human setting (in dogs), ${ }^{13}$ and its first mention in a review of platelet function assays. ${ }^{14}$

Over the following 10 years, the PFA-100 continued to gather interest (Fig. 1) and has by now featured in nearly 500 publications and some 35 reviews, including several reviews by this author. ${ }^{15-18}$ It is of some interest to note how popular the PFA-100, in essence a fairly simple conceptual device, has become in clinical hemostasis diagnostics. ${ }^{19}$ It is also of interest to identify how widely the PFA-100 has been used by scientists and clinical researchers, and so a summary of this is provided in Table 1. Nevertheless, this review is not meant to be an exhaustive synopsis of all the literature related to the PFA-100 but rather will focus on several major clinical applications.

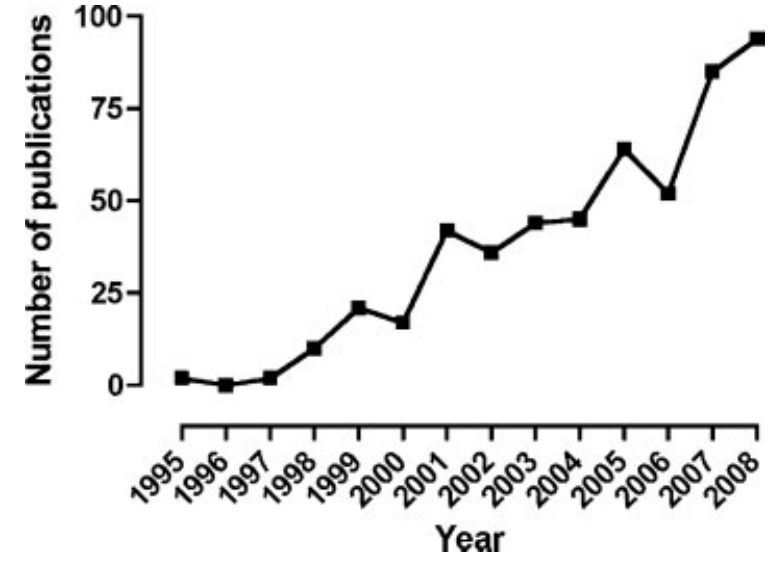

Figure 1 The rise and rise of the PFA-100. Number of publications by year related to use of the PFA-100 according to a Medline search as of the end of June 2008. Data for 2008 is extrapolated from 6 months of data and assumes a similar rate of publication until the end of the year.

\section{GENERAL ANALYTICAL AND PREANALYTICAL CONSIDERATIONS}

Classic platelet activity testing (i.e., platelet aggregation or platelet function studies; PFSs) involves a very laborintensive process and a highly technically skilled operator. The process typically uses an instrument called a platelet aggregometer. Depending on the kind of methodology employed, PFSs are performed using either whole blood (typically citrate anticoagulated) or whole blood processed by selective centrifugation to obtain a platelet-rich plasma fraction. This material is then "challenged" using various platelet agonists (usually

Table 1 Use of the PFA-100 by Scientists and Clinical Researchers: A Summary of Applications

\begin{tabular}{|c|c|}
\hline Broad Application & Comments \\
\hline Animal studies & $\begin{array}{l}\text { More than } 20 \text { studies in animals, primarily dogs, but also including camels, } \\
\text { horses, pigs, and hamsters; studies have included assessment of aspirin } \\
\text { effects (dogs), cardiac disease (dogs), pollution (hamsters), anesthetics (pigs), } \\
\text { and the identification of a case of Glanzmann thrombasthenia (horse) }\end{array}$ \\
\hline $\begin{array}{l}\text { Assessment of } \\
\text { bleeding risk and therapy }\end{array}$ & See main text; including surgery, WWD, and platelet function \\
\hline Assessment of thrombotic risk & $\begin{array}{l}\text { See main text; primarily in relation to potential failure of aspirin therapy, } \\
\text { but increasingly investigated as a marker of thrombophilia }\end{array}$ \\
\hline $\begin{array}{l}\text { Assessment of drug therapy, } \\
\text { drug effects, or other agents }\end{array}$ & $\begin{array}{l}\text { See main text; primarily aspirin, but also clopidogrel, nonsteroidal anti-inflammatory } \\
\text { drugs (NSAIDs; e.g., diclofenac, lornoxicam, rofecoxib, nabumetone, meloxicam, } \\
\text { indomethacin, ibuprofen), contrast media (iopromide, ioxaglate, gadolinium-DOTA), } \\
\text { anesthetics (propofol, xenon, ropivacaine hydrochloride), antithrombotics (ticlopidine, } \\
\text { tirofiban, abciximab), other compounds (IFN- } \alpha \text {, endotoxin, heparin, valsartan, triflusal, } \\
\text { eptifibatide, beraprost, epoprostenol, vasoactive intestinal peptide, aurintricarboxylic acid, } \\
\text { alcohol, erythropoietin, strontium ranelate, licofelone, raloxifene) }\end{array}$ \\
\hline $\begin{array}{l}\text { Assessment of herbal medicines } \\
\text { or extracts or dietary agents }\end{array}$ & $\begin{array}{l}\text { Various flavonoids, Ginkgo biloba, garlic, Asian ginseng, St. John's wort, saw palmetto, } \\
\text { chocolate/cocoa, p-coumaric acid (a common dietary phenol) }\end{array}$ \\
\hline $\begin{array}{l}\text { Assessment of blood expander/ } \\
\text { replacement agents }\end{array}$ & $\begin{array}{l}\text { Including dextran sulfate, colloids, and crystalloids; also for quality control of platelet } \\
\text { concentrates }\end{array}$ \\
\hline
\end{tabular}


ADP, collagen, ristocetin, arachidonic acid; occasionally also epinephrine, thrombin, and other agonists) and resulting platelet adhesion and/or platelet aggregation assessed. ${ }^{20}$ So-called platelet release studies (analyzing whether the platelets are further capable of releasing various internal stored material) may also be performed.

Although potentially of use for a variety of possible bleeding disorder testing applications (including assessment and classification of VWD, assessment of platelet dysfunction, efficacy of aspirin or other antiplatelet drug treatment, or as an alternative to performance of SBTs), classic PFS is not generally recommended as a test of first choice. There are many reasons for this, including the general lack of specificity and sensitivity, the level of testing complexity, and the laboratory time consumed. ${ }^{20}$ Indeed, because of such considerations, classic PFS is often a test of last resort (e.g., may be indicated to further classify type $2 \mathrm{VWD}$ or else to test for a potential rare platelet disorder after VWD has been discounted by specific and sensitive testing).

Accordingly, the PFA-100 was developed to provide an alternative to, or to supplement the need to perform, classic PFS in select circumstances. The PFA100 uses whole blood flow through a capillary device to mimic high shear stress conditions that occur in vivo (i.e., is said to "simulate" primary hemostasis) and gives a single end-point reading. The theoretical maximum CT is 300 seconds, but for practical purposes any value reported as greater than 250 to 300 seconds can be considered as "maximally" prolonged (or equivalent to "nonclosure"). The PFA-100 is variably sensitive to different hemostatic defects and medication effects. The PFA-100 is also sensitive to platelet deficiencies and hematocrit disturbances. The C/Epi tends to be the more sensitive of the two test cartridges, yielding longer $\mathrm{CT}$ s than does the C/ADP cartridge in most test cases. To some extent, the degree of CT prolongation and the pattern of test results both help to identify the potential severity of hemostatic disorders and the likelihood of a medication-related effect. Thus, CTs with both test cartridges will be grossly prolonged in severe VWD or severe platelet dysfunction (e.g., Bernard-Soulier syndrome [BSS] or Glanzmann thrombasthenia [GT]), and a grossly prolonged $\mathrm{C} / \mathrm{Epi} \mathrm{CT}$ with a normal C/ADP $\mathrm{CT}$ will often pinpoint an aspirin effect. A moderately prolonged C/Epi CT with a normal C/ADP CT may still point to an aspirin effect or otherwise to possible mild VWD or platelet dysfunction. The possibility of a low platelet count or low hematocrit should, however, also be considered.

\section{Blood-Collection Issues}

Blood for testing by the PFA-100 is collected into sodium citrate anticoagulant, of which two main concentrations are available $(0.109$ and $0.129 \mathrm{mM}$; some- times referred to as $3.2 \%$ and $3.8 \%$, respectively). Although $3.2 \%$ is generally preferred for hemostasis applications, ${ }^{21} 3.8 \%$ might be preferred for assessing aspirin effects in the PFA-100 and appears to provide greater stability in CT readings as well as better reproducibility in perceived response. ${ }^{22,23}$

\section{Blood-Processing Issues}

After collection, blood should be transported to the laboratory in a timely manner, at ambient temperature (i.e., $15^{\circ} \mathrm{C}$ to $\left.25^{\circ} \mathrm{C}\right){ }^{21}$ Transport under extremes of temperature (viz., cooled conditions [i.e., refrigerated] or high temperatures [i.e., $>25^{\circ} \mathrm{C}$ ]) should be avoided, as these will compromise testing. Transport by pneumatic tube should also be avoided, especially if assessing any aspirin-related effects. ${ }^{24}$ Samples must not be centrifuged. Although this might appear obvious to us, there is a broad general tendency for processing laboratories to automatically centrifuge all "blue-top coagulation" samples. On occasion, processing laboratories may inadvertently centrifuge a PFA-100 sample as a "coagulation" sample and attempt to "fix" the problem by subsequent tube inversions to reconstitute the whole blood. This is inappropriate; once centrifuged, test samples are no longer suitable for PFA-100 testing due to platelet activation.

Testing with the PFA-100 should be conducted no sooner than 15 minutes after blood collection and no later than 5 hours after collection. The former time recommendation appears to relate to a need for blood to equilibrate and "stabilize" within the blood-collection tube anticoagulation system after vacuum tube collection. The latter time recommendation represents the known stability limits for this test.

\section{Variance in Normal Reference Ranges}

Given its higher sensitivity, the normal range for the $\mathrm{C} / \mathrm{Epi} \mathrm{CT}$ also tends to be broader with a higher upper limit than that of the C/ADP CT. The normal reference range (NRR) for the CT should ideally be established or verified at each individual test center. Interestingly, there is some evident variation in the NRR as established by various laboratories or various studies, with some examples given in Tables 2 and 3. Consideration of the NRR is not just academic. A NRR will define both the "normal" population (below the upper limit of the NRR) and the "disease" or "medication" affected population (above the upper limit of the NRR). Thus, selection of an inappropriate NRR may inflate or falsely underestimate disease or medication effects. Although it can be assumed that published studies would use local "normals" (i.e., otherwise healthy individuals, no recent medication) to establish their own NRR, the differences between studies presumably reflect local differences in 


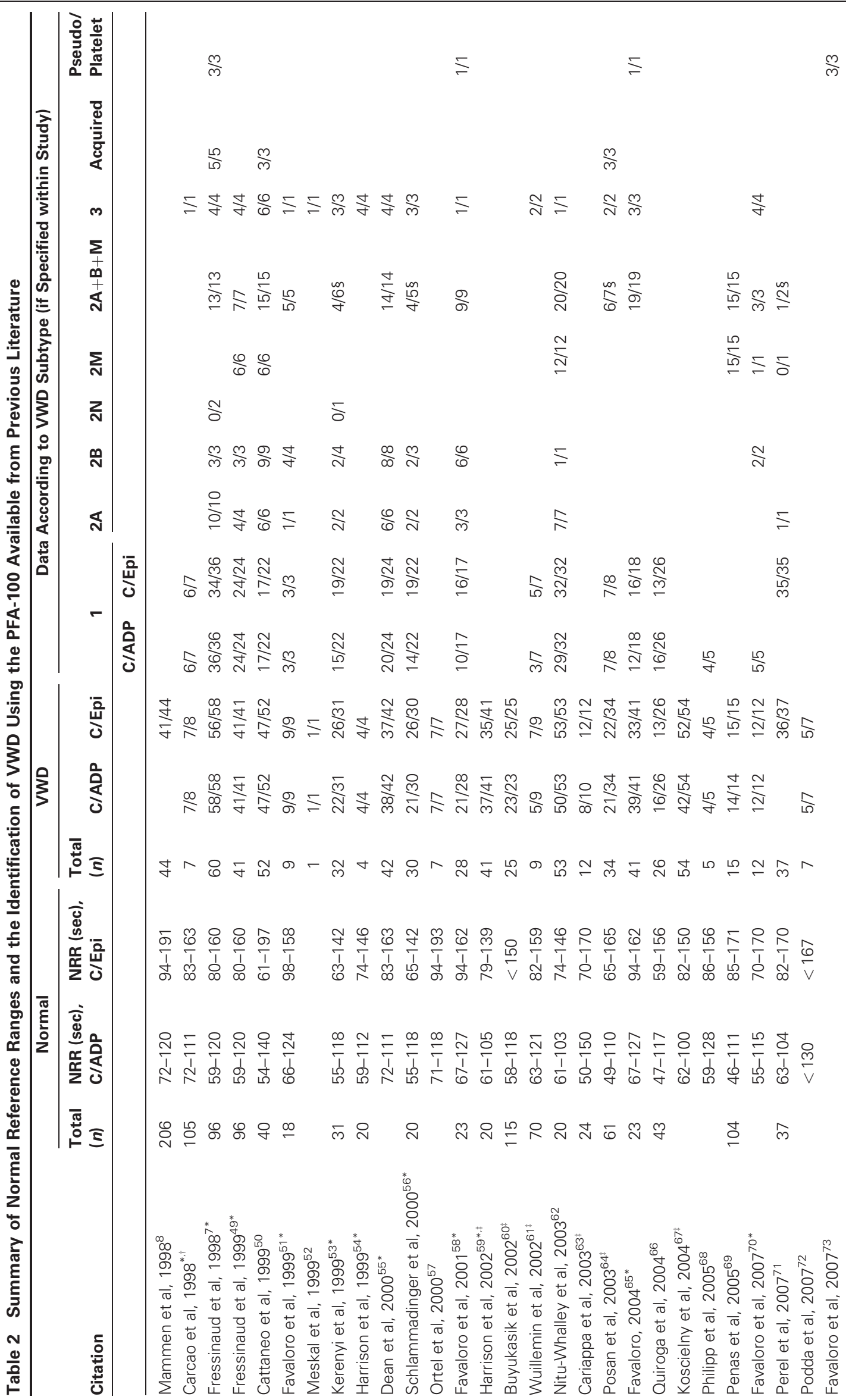


"healthy individual selection," as well the many other test variables noted within this article.

\section{Gender, Age, Smoking, Oral Contraceptives, Pregnancy, and Various Blood Parameters}

The PFA-100 CT was originally reported as not being influenced by either gender ${ }^{25}$ or oral contraceptive use. ${ }^{25,26}$ However, a more recent study in Korean individuals did determine a gender effect, with females showing a significantly longer $\mathrm{CT}$ with both $\mathrm{C} / \mathrm{Epi}$ and C/ADP than that of males. ${ }^{27} \mathrm{~A}$ slight elevation in $\mathrm{CT}$ using the $\mathrm{C} /$ Epi cartridge has been noted in smokers compared with nonsmokers, with this possibly being gender related. ${ }^{25,28}$ The PFA-100 CT was also originally reported as not correlating with age. ${ }^{26}$ However, older males (i.e., $>55$ years) have been reported to have a shorter CT than that of younger males, ${ }^{26}$ older Koreans (i.e., $>40$ years) have been reported to have a shorter CT than that of younger Koreans, ${ }^{27}$ and newborns or neonates have relatively short CTs compared with those of school-age children and adults. ${ }^{9-11}$ Nevertheless, pediatric ranges are not expected to be dissimilar to adult ranges. $9,10,29$

Shorter PFA-100 CTs have also been noted in pregnant woman compared with that in nonpregnancy. ${ }^{12,30-33}$ Ovarian cycle changes have also been noted by researchers. ${ }^{34} \mathrm{ABO}$ blood group effects are of additional interest, with $\mathrm{O}$-group individuals showing longer $\mathrm{CT}$ s than that of non-O-group individuals. ${ }^{27,35-39} \mathrm{PFA}-$ 100 CTs have also been reported to follow a diurnal pattern, with CT values increasing over the day. ${ }^{27,40}$ The effect of exercise on PFA-100 CTs has also been evaluated $^{41-43}$ and generally shown to have no significant effect, although it has also been noted that elite athletes tend to have shorter relative $\mathrm{CT}$ s than that of the general population.

Some early studies reported a lack of significant correlation between CT and hematocrit, platelet count, mean platelet volume or leukocyte count, or else reported differential correlations. Within this context, it is important to reflect on the study design and the relative inclusion or exclusion of abnormal test parameters. In actual fact, many blood parameters may affect the PFA-100 CT, particularly when levels fall below normal. Thus, low hematocrit levels, low platelet counts, and low leukocyte counts can all lead to prolongation of $\mathrm{CT}$, and correlation will be observed when these data are included with the normal data set, as previously reported. ${ }^{15,16} \mathrm{It}$ is important that this be recognized to avoid a potential misinterpretation of an "abnormal" $\mathrm{CT}$ as a primary hemostatic disorder.

The PFA-100 is not sensitive to defects or deficiencies in fibrinogen or the other classic coagulation factors (including factors VIII, IX, and XI). ${ }^{15,16}$ It is therefore not useful for assessing hypofibrinogenemia, 


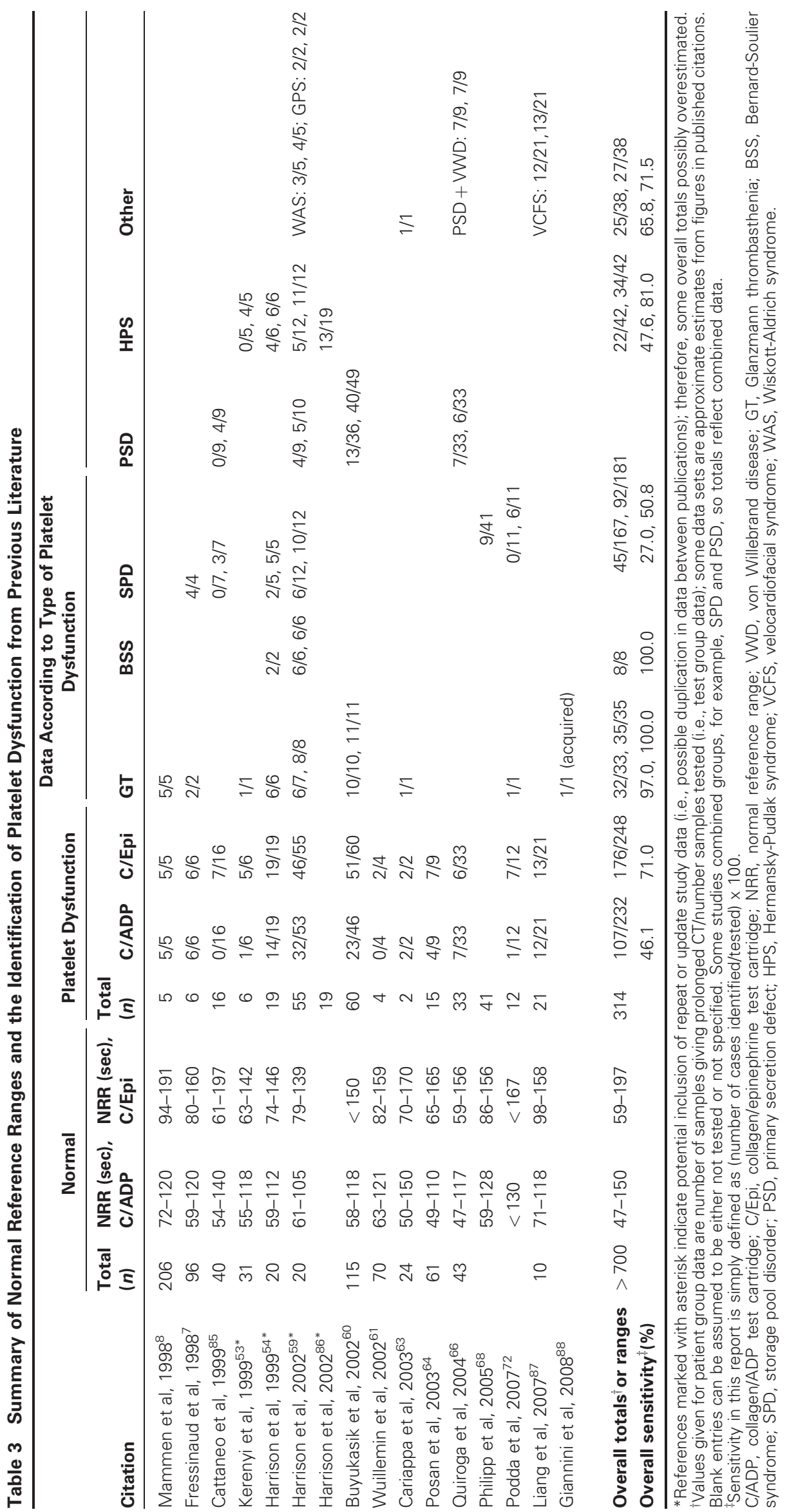


dysfibrinogenemia, or classic hemophilia (i.e., hemophilia A, B).

\section{Heparin and Vitamin K Antagonist Therapy}

The CT is not influenced by the presence of heparin, unless very high concentrations are used ${ }^{44-46}$ (also current author's unpublished findings). PFA-100 CTs are also generally normal in patients on vitamin $\mathrm{K}$ antagonist therapy ${ }^{47}$ (also current author's unpublished findings).

\section{Sensitivity to von Willebrand Factor}

It is most important to recognize that the PFA-100 is very sensitive to the influence of plasma von Willebrand factor (VWF) and that CTs will increase or decrease according to the level of VWF presenting. Indeed, there is a very strong inverse relationship between plasma VWF and PFA-100 CTs. ${ }^{15-17}$ Whereas it may be obvious that CTs may be prolonged when VWF is low or absent (i.e., as in VWD), it is less well appreciated that CTs may be short when VWF levels are high. This may influence the NRR and have other less-well recognized effects. For example, people with $\mathrm{O}$-group blood tend to have higher PFA-100 CTs than that of non-O-group individuals and also correspondingly lower levels of plasma VWF. PFA$100 \mathrm{CTs}$ are shorter in neonates, in the elderly, and in pregnant women. Accordingly, it should no longer come as a surprise that plasma VWF levels are correspondingly high in neonates and in pregnancy and also increase in later age. There is also a reported diurnal relationship for $\mathrm{CT}$ (shorter in the morning than in the afternoon). ${ }^{27,40}$ Interestingly, plasma VWF has been reported to peak at midday. ${ }^{48}$ The relationship between the CT and plasma VWF also has a strong (and generally underrecognized) influence on the sensitivity of the PFA-100 to drugs including aspirin.

\section{Sensitivity of the PFA-100 to Medications and Drug Effects: Monitoring Versus Analytical Variable?}

A range of medications variably influence the $\mathrm{CT}$, and this has led to use of the PFA-100 in the clinical monitoring of some of these. In particular, aspirin, which has long been known to have antiplatelet activity, can strongly influence CT results, and this has resulted in many studies investigating the potential use of the PFA-100 in monitoring aspirin therapy or otherwise noting aspirin-like effects. Other medications are also known to influence the PFA-100 CT, or alternatively, the PFA-100 may play a role in their clinical monitoring. Essentially, any medication that can influence platelet activity or VWF levels or function may fall into this category. This is explored in some detail in a subsequent section of this review.

\section{ROLE OF THE PFA-100 IN THE IDENTIFICATION AND TREATMENT OF DISORDERS OF PRIMARY HEMOSTASIS}

There have been a large number of studies assessing the sensitivity of the PFA-100 to disorders of primary hemostasis, including VWD and various platelet abnormalities, as summarized in Tables 2 and 3. Some studies have assessed both VWD and platelet disorders, and others have targeted specific disorders selectively. Some studies have also evaluated the effect of therapy on PFA$100 \mathrm{CTs}$ in these disorders, typically using either DDAVP or factor concentrate therapy.

\section{Role of the PFA-100 in the Identification of VWD} The role of the PFA-100 in the identification of VWD is summarized in Table 2. Readers are also directed to earlier specific reviews by this author on this topic. ${ }^{15-17}$ Although some studies have replicated data, these studies have in total assessed more than 1000 normal individuals and around 600 individuals with VWD. There are a few important considerations to note. First, there is fairly broad agreement between most reports in terms of data findings. Second, in keeping with its general higher sensitivity, the $\mathrm{C} / \mathrm{Epi}$ test cartridge is more sensitive to VWD than is the C/ADP test cartridge, and this becomes particularly evident when assessing potentially milder forms of VWD (i.e., primarily type 1). Overall sensitivity of the PFA-100 to VWD is around 85 to $90 \%$, with sensitivity to type 1 VWD being related to the presenting plasma level of VWF (i.e., PFA-100 CT is more sensitive to severe VWD than to moderate VWD). All type 2A VWD cases, representing those with a relative loss of highmolecular-weight (HMW) VWF (and usually also intermediate-molecular-weight VWF), reported to date have been identified to give abnormal CTs. The vast majority of type $2 \mathrm{~B}$ and type $2 \mathrm{M}$ VWD cases have also been identified to yield prolonged CTs. Indeed, normal CTs in such cases is very rare and has only been reported in a few isolated studies, suggesting that these were either unusual cases or that they were possibly misidentified. All type 3 VWD cases reported to date have also been identified to give abnormal CTs, as have all reported platelet-type (pseudo-) VWD. As expected, and given that a low plasma level of FVIII is the major phenotypic presentation in type $2 \mathrm{~N}$ VWD, the PFA-100 is not sensitive to type $2 \mathrm{~N}$ VWD, unless this is of a composite VWD subtype that also presents with low levels of VWF.

The PFA-100 has been identified as more sensitive to VWD than is the SBT with some reasonable consistency ${ }^{7,50,55,56,61,63,64,66-69,72}$ (also summarized in previous reviews). ${ }^{15,16}$ Also, where studies have included both normal individuals and patients with VWD, workers have commented on the strong correlation between 
PFA-100 CT results and various VWF parameters, including VWF antigen (VWF:Ag), VWF ristocetin cofactor (VWF:RCo), and/or VWF collagen binding (VWF:CB) (summarized in previous reviews). ${ }^{15-18}$

A recently published systematic review and metaanalysis on the diagnostic performance of the PFA-100 for the detection of disorders of primary hemostasis including VWD has also assessed the sensitivity, specificity, and positive and negative predictive value of the PFA-100. ${ }^{74}$ This meta-analysis used strict study inclusion criteria such as consecutive enrollment or random selection (to avoid selection bias) with reported evidence of a primary hemostatic bleeding disorder that permitted evaluation of "true positives," "true negatives," "false positives," and "false negatives." Accordingly, this meta-analysis was only able to include data from six studies, primarily prospective studies as differentially identified within Table 2. Interestingly, the sensitivities identified in the different studies included were broadly similar to each other and to pooled data from Table 2, except for the relatively small study by Wuillemin et al. ${ }^{61}$ Although the meta-analysis provides for an interesting report, there are limitations to such an approach as it relates to diagnosis of VWD. First, such an analysis assesses the ability of the PFA-100 CT to identify VWD in an individual presenting with a primary hemostatic bleeding disorder without reference to whom the patient is referred and without reference to other potential compounding factors. In the real world of clinical investigation, potential patients for investigation would present to a multitude of clinical generalists or specialists, including emergency physicians, anesthetists, surgeons, generalist hematologists, and specialist hematologists. Each clinical group would represent an inherent patient selection (or referral) bias and would also have a different clinical perspective on perceived "primary hemostatic disorders" based on local knowledge or personal experience. The less well selected the patient cohort, or the less knowledgeable the clinician in terms of identifying significant hemostasis defects, then the poorer will be the perceived sensitivity of the PFA-100.

This author does not advocate use of the PFA100 to screen patients for a theoretical hemostatic defect in unselected patients. In addition, in the real world of PFA-100 testing, consideration should always be given to strict evaluation of recent patient medication (given that the PFA-100 is sensitive to many drugs), and testing should be avoided if the patient is not medication free, or else this needs to be taken into account when assessing CT data. Furthermore, a complete blood count should always be performed to assess for lowered hematocrit or lowered platelet count and this also taken into account when assessing CT data. In other words, although it is true that better patient selection will potentially inflate perception of PFA-100 sensitivity, specific patient selection (or diagnostic targeting) would be the recommended approach. Interestingly, the studies ultimately used by this meta-analysis tended to provide the poorest identification of VWD subtypes (Table 2) and thus tended to be among the least useful in specific VWD subgroup analysis.

\section{Role of the PFA-100 in Monitoring Treatment for VWD}

The current preferred choices for therapeutic support of individuals with VWD are DDAVP and/or factor VIII/ VWF concentrate, depending on efficacy. If appropriate for the VWD subtype, DDAVP is generally favored, as it acts to cause release of the individual's own stored VWF. Unfortunately, it is not effective, or not adequately effective, in all VWD patients. Although it is sometimes possible to predict which patients will or will not appropriately respond, it is usual to conduct a "trial" of (or challenge patients with) DDAVP and then to monitor their response by subsequent blood sampling. ${ }^{18}$ DDAVP is usually effective for most patients with type 1 VWD and in some patients with type 2 VWD. It is not effective in type 3 VWD, as these individuals do not produce VWF, nor is it effective for a subset of type 1 (usually VWF "platelet-low" or "platelet-discordant" types) or for a subset of type 2 patients (difficult to predict). Those individuals who do not appropriately respond to DDAVP are managed using factor replacement, and typically factor VIII/VWF concentrate.

The role of the PFA-100 in the monitoring of therapy for VWD has also been evaluated by several studies, ${ }^{49,50,74-84}$ and has previously been summarized by this author. ${ }^{15-18}$ Where evaluated, PFA-100 CT responses also tended to provide more utility than did the SBT. For DDAVP, PFA-100 CT corrections depend on the type of VWD and tend to reflect correction of functional VWF, notably that detected by the VWF:CB. ${ }^{18,76,83,84}$ Thus, for VWD patients with an abnormal baseline CT, DDAVP is generally able to normalize the CT for most type 1 VWD individuals, but only for some type 2 VWD individuals. The response of the PFA-100 to factor concentrate therapy, as provided to DDAVP nonresponders, is less striking. Thus, CT values may not normalize in the setting of factor concentrate therapy despite correction of "functional" VWF, depending on the factor concentrate and the concentration used. In brief, normalization of CT will preferentially occur using higher concentrations of factor concentrates than that normally applied in therapy, and CT correction may also be dependent on the factor concentrate composition, with those concentrates yielding compositions better reflective of the complete set of VWF multimers, including HMW forms, being those most likely to correct the CT. Whether this is clinically relevant is currently unproved, but logic suggests that this will indeed be the case. 
In summary, the PFA-100 has a potential role in monitoring DDAVP therapy, but current instrumentation is insufficiently sensitive to factor concentrate therapy. Normalization of abnormal PFA-100 CTs tends to mimic normalization of plasma VWF, in particular functional VWF assessed in vitro using the VWF:CB assay, and most likely because this assay best reflects the functional adhesive activity of HMW VWF. ${ }^{18,76,83,84}$ Nevertheless, lack of correction of PFA-100 CT does not necessarily reflect treatment failure, and appropriate prospective studies are still required to definitively identify the role of the PFA-100 in this setting.

\section{Role of the PFA-100 in the Identification of Platelet Function Defects}

The role of the PFA-100 in the identification of platelet function defects is summarized in Table 3. Compared with VWD discussed previously, there are fewer studies and less replication in data. Some of the studies identified in Table 3 also reported on VWD (Table 2). In total, studies summarized in Table 3 have assessed more than 700 normal individuals and around 300 individuals with various congenital platelet disorders. There are a few additional important considerations to note. First, like the case with VWD, there is again fairly broad agreement between different reports in terms of data findings, and the PFA-100 is most sensitive to cases that would appear more severe in terms of bleeding presentation, namely GT and BSS. Indeed, all cases of BSS reported to date have been identified to give abnormal CTs, as have all but a single case of GT. In terms of the latter, it is feasible that this might have more likely represented a "glitch" in PFA-100 testing than a true test result. In contrast with test findings with these severe forms of platelet dysfunction, and also analogous to the case for VWD, PFA-100 CT data for milder platelet disorders is more varied and also shows poorer sensitivity. Although some studies provide separate data for storage pool disorders (SPDs) and primary secretion defects (PSDs), other studies provided only combined data. Nevertheless, sensitivity of the PFA-100 to both of these conditions appears to be similar, and around only half of tested cases will give an abnormal C/Epi CT, and fewer cases still (around a quarter) will give an abnormal C/ADP CT. The PFA100 appears to be marginally more sensitive to Hermansky-Pudlak syndrome (HPS), giving abnormal CTs with $\mathrm{C} / \mathrm{ADP}$ or with $\mathrm{C} / \mathrm{Epi}$ in around $80 \%$ and $50 \%$ of cases, respectively. In contrast to the situation with VWD, the sensitivity of the PFA-100 to platelet function disorders is considered overall to be fairly similar to that of the SBT, ${ }^{63,64,66-68,72,89}$ although it should be recognized that the latter is a more invasive test procedure. In any case, given the relative insensitivity of the PFA-100 and the SBT to mild platelet function disorders, neither can be recommended to screen for these cases.

\section{Role of the PFA-100 in the Monitoring of Treatment for Platelet Function Defects}

The role of the PFA-100 in the monitoring of therapy for platelet function disorders using DDAVP therapy has also been evaluated by a limited number of studies. ${ }^{78,81,82,85}$ DDAVP therapy is clinically useful for some platelet disorders, and notably SPDs and PSDs. In such individuals, baseline SBT and C/Epi CT (but not $\mathrm{C} / \mathrm{ADP} \mathrm{CT}$ ) tend to be prolonged. DDAVP will generally increase VWF, normalize the $\mathrm{C} / \mathrm{Epi} \mathrm{CT}$, and shorten the C/ADP CT. Nevertheless, lack of correction of PFA-100 CT does not necessarily reflect treatment failure, and appropriate prospective studies are still required to definitively identify the role of the PFA-100 in this setting.

\section{DOES THE PFA-100 HAVE A MORE GENERAL ROLE IN ASSESSING SURGICAL BLEEDING RISK?}

This is a poorly investigated potential indication for the PFA-100. Koscielny et al ${ }^{67,78}$ recently reported a large prospective study where they investigated a total of 5649 unselected adult patients presenting for surgery (variety of procedures), with each asked to answer a standardized questionnaire concerning bleeding history. The PFA-100 CT (both C/Epi and C/ADP) was evaluated in all patients, together with platelet counts and routine coagulation tests (i.e., activated partial thromboplastin time [APTT] and prothrombin time $[\mathrm{PT}]) .{ }^{67} \mathrm{SBT}$ s and VWF:Ag were performed only in patients with a positive bleeding history and/or evidence of impaired hemostasis. The bleeding history was negative in $5021(88.8 \%)$ patients but positive in the remaining $628(11.2 \%)$ patients. ${ }^{67}$ Impaired hemostasis could be verified by laboratory testing in only 256 $(40.8 \%)$ of these patients. The vast majority was identified with the PFA-100 using the C/Epi cartridge $(n=250 ; 97.7 \%)$. The other six patients with impaired hemostasis were identifiable solely based on the PT $(n=2), \mathrm{C} / \mathrm{ADP} \mathrm{CT}(n=2)$, and VWF:Ag $(n=2)$. The C/ADP CT detected 199 (77.7\%) patients overall. The only abnormality found among patients with a negative bleeding history was a prolonged APTT due to lupus anticoagulant in nine $(0.2 \%)$ patients. The sensitivity of the PFA-100 C/Epi CT was the highest (90.8\%) in comparison with the other screening tests (SBT, APTT, PT, VWF:Ag). The positive predictive value of the C/Epi CT was high (81.8\%), but the negative predictive value was higher (93.4\%). They concluded that use of a standardized questionnaire and, if indicated, the PFA-100 C/Epi and/or other specific tests was able to ensure the detection of impaired hemostasis in almost every case where laboratory testing contributed to its detection. In a further analysis, ${ }^{78} 254$ of these 5649 unselected patients were preoperatively 
identified as having either acquired $(n=182)$ or inherited $(n=72)$ impaired primary hemostasis (platelet dysfunction including VWD). All patients were initially pretreated with DDAVP. Response to DDAVP or to subsequent treatment(s) was defined as correction of any one of the abnormal PFA-100 tests. The nonresponders were additionally treated with tranexamic acid or aprotinin, and nonresponders with VWD received factor VIII/VWF concentrates. Those still unresponsive to therapy received conjugated estrogens and, as a last attempt, a platelet transfusion. The administration of DDAVP led to a correction of PFA-100 defined "platelet dysfunction" in 229 of the $254(90.2 \%)$ patients treated. Tranexamic acid was effective in 12 of 16 , aprotinin in 3 of 5 , and factor VIII/VWF concentrates in all 4 patients with VWD unresponsive to DDAVP. The remaining six patients were pretreated with conjugated estrogens, and two of these patients were additionally treated with platelet transfusion. The frequency of blood transfusion was lower but not statistically significant $(9.4 \%$ vs. $12.2 \%$ : $p=0.202)$ in preoperatively treated patients with impaired hemostasis compared with that in those without impaired hemostasis. In a retrospective group, the frequency of blood transfusion was statistically significantly higher $(89.3 \%$ vs. $11.3 \%: p<0.001)$ in patients without preoperative correction of impaired hemostasis compared with that in those without impaired hemostasis. The authors concluded that preoperative correction of impaired primary hemostasis, as identified by bleeding history and subsequent laboratory testing, was possible in nearly all patients affected and resulted in a reduction of homologous blood transfusions.

Most surgical studies assessing the potential role of the PFA-100 in assessing bleeding risk have involved cardiac procedures. Wahba et $\mathrm{al}^{90}$ investigated the suitability of the PFA-100 and the Hepcon HMS (Medtronic Inc., Minneapolis, MN) to predict blood loss after operations with extracorporeal circulation (ECC) and compared these with conventional coagulation studies. Using 40 patients subjected to elective open heart surgery with ECC, a blood sample was taken before and after ECC to measure platelet count, PT, APTT, D-dimer, fibrinogen, PFA-100, and Hepcon HMS data. The postoperative blood loss was recorded hourly until removal of drains. A significant correlation was found between total blood loss (250 to $1750 \mathrm{~mL}$ ) and the preoperative PFA-100 CT $(\mathrm{r}=0.41, p=0.022)$, the preoperative platelet count $(\mathrm{r}=-0.42, p=0.007)$, the preoperative $\mathrm{D}$-dimer concentration $(\mathrm{r}=0.41$, $p=0.01)$, and duration of ECC $(\mathrm{r}=0.35, p=0.044)$. There was no significant correlation between blood loss and the Hepcon HMS system. They concluded that although a significant correlation was found between blood loss and the PFA-100 CT, the practical value of these tests in the clinical situation was limited because of a great variability in individual results.

Lasne et $\mathrm{al}^{91}$ assessed the ability of the PFA-100 to predict increased bleeding risk in 146 patients undergoing primary coronary artery bypass (CPB) graft. Blood samples were taken the day before surgery and 15 minutes and 5 hours after heparin neutralization. The preoperative $\mathrm{CT}$ using $\mathrm{C} / \mathrm{Epi}$ or $\mathrm{C} / \mathrm{ADP}$ were longer in blood-group-O patients than in patients with other blood groups. The 15-minute postoperative values were significantly longer than the preoperative values essentially owing to CPB-induced hemodilution. Five hours after $\mathrm{CPB}$, a significant reduction in $\mathrm{CT}$ values was identified and thought to reflect platelet hyperaggregability. No correlation was found between calculated blood loss and either preoperative or postoperative PFA-100 CT values.

Forestier et $\mathrm{al}^{92}$ assessed the PFA-100 and the Hemostatus (Medtronic Inc., Minneapolis, MN) in patients with and without excessive bleeding after cardiac surgery with $\mathrm{CPB}$ by measuring mediastinal chest tube drainage (MCTD) for the first 6 hours in the intensive care unit (ICU). Eighteen patients bled excessively and 27 patients had normal MCTD. Hemostatus measurements were prolonged in those with excessive bleeding compared with those in the normal group. PFA-100 CT for $\mathrm{C} / \mathrm{ADP}$ and $\mathrm{C} / \mathrm{Epi}$ were 91 versus 71 seconds $(p=0.004)$ and 155 versus 114 seconds $(p=0.02)$ in the bleeding and normal groups, respectively. None of the Hemostatus or PFA-100 values correlated with total MCTD. The authors concluded that patients bleeding excessively in the ICU had abnormal measurements in both point-of-care tests, but except for patients with increased risk of post-bypass bleeding, these pointof-care tests were not useful for routine use after cardiac surgery.

Fattorutto et $\mathrm{al}^{93}$ also evaluated whether the PFA-100 could be used to predict blood loss after cardiac surgery. They drew blood samples from 70 patients before and after $\mathrm{CPB}$. They observed a weak correlation between pre-CPB C/Epi CT and secondhour mediastinal blood loss $(r=0.34, p=0.01)$. The sensitivity and positive predictive value of the PFA-100 measurements were comparable with those of platelet count for predicting excessive bleeding after CPB (75\% and $27 \%$ vs. $100 \%$ and $25 \%$, respectively). They concluded that the PFA-100 might be useful for detecting patients who could have excessive bleeding after $\mathrm{CPB}$, but that the PFA-100 was not able to separate patients at low risk of subsequent bleeding from those who had substantial bleeding.

Cammerer et $\mathrm{al}^{94}$ assessed the predictive value of the PFA-100 based on rotational thromboelastography (ROTEG; Pentapharm, Munich, Germany) analysis for postoperative bleeding after routine cardiac surgery in a prospective study of 255 consecutive patients. 
Measurements were performed at three time points: preoperatively, during $\mathrm{CPB}$, and after protamine administration. The best predictors of increased bleeding tendency were the tests performed after CPB. Thromboelastography was a better predictor than the PFA100, particularly after cardiopulmonary bypass, but positive prediction was only moderate, and there were several other limitations identified. Thus, impaired hemostasis as identified by these tests did not inevitably lead to hemorrhage postoperatively, and a surgical cause was most likely the reason for bleeding in patients with normal test results. Thus, there was a high negative predictive value for postoperative bleeding, which supported early identification and targeted treatment of surgical bleeding by distinguishing these from a significant coagulopathy.

Avidan et $\mathrm{al}^{95}$ evaluated the use of algorithms based on point-of-care coagulation tests to assess whether these could decrease blood loss and blood component transfusion after cardiac surgery. One hundred two patients undergoing $\mathrm{CPB}$ were randomized into two groups. In the point-of-care group, the management algorithm was based on information provided by three devices, the Hepcon, thromboelastography, and the PFA-100. Management in the laboratory test group depended on rapidly available laboratory clotting tests and transfusion of hemostatic blood components only if specific criteria were met. Blood loss and transfusion was compared between these two groups and with a retrospective case-control group $(n=108)$ in which management of bleeding had been according to the clinician's discretion. All three groups had similar median blood losses. The transfusion of packed red blood cells and blood components was greater in the clinician discretion group $(p<0.05)$, but there was no difference in these parameters between the two algorithm-guided groups. They concluded that algorithms based on point-of-care tests or on structured clinical practice with standard laboratory tests did not decrease blood loss but did reduce transfusional needs compared with that in the clinical discretion group.

Hertfelder et $\mathrm{al}^{96}$ evaluated the potential of the PFA-100 in perioperative monitoring on 49 patients selected for low bleeding risk undergoing selective primary CPB grafting. They compared the PFA-100 with the SBT and platelet aggregometry and further analyzed global hemostasis by thromboelastography (TEG) and plasma-based coagulation by standard clotting tests (PT, APTT, thrombin time [TT], and clotting factors) and fibrinolysis by Reptilase time (RT; batroxobin). In all patients, SBT increased postoperatively by 1.5 - to 2 -fold irrespective of perioperative complications and then decreased to mildly prolonged values on the first postoperative day (+day 1). In patients without complications, PFA-100 CTs using both $\mathrm{C} / \mathrm{ADP}$ and $\mathrm{C} /$ Epi remained nearly stable before and after surgery. Apart from a single patient with postoperative moderate thrombocytopenia, no other significant defect of PFA-100 CTs was observed. However, on +day 1, the PFA-100 CT of those patients with bleeding was significantly increased compared with that in nonbleeding patients. In patients with postoperative myocardial ischemia, increased "platelet activity" was identified by significantly shorter postoperative C/ADP CT compared with that in uncomplicated patients. By aggregometry, partial platelet dysfunction was observed in some patients without correlation to bleeding complications. In seven of nine patients, the postoperative bleeding complication was attributed to prolonged heparin anticoagulation and/or mildly enhanced fibrinogenolysis/fibrinolysis by TEG and standard coagulation tests. The impairment of "platelet activity" using the PFA-100, platelet aggregation, and clotting factors observed on +day 1 in bleeding patients were thought most likely secondary effects due, for example, to loss of active platelets and clotting factors, or to the primary postoperative bleeding. Hertfelder et al concluded by suggesting that in standard $\mathrm{CPB}$ procedures, highly variable alterations of the hemostatic system can occur even in patients with assumed low operative risks. For identification of post-CPB bleeding complications, TEG, APTT, TT, and heparin and RT as hemostasis and fibrinolysissensitive assays were useful, and platelet function appeared to be rapidly restored in uncomplicated CPB surgery. They also believed that PFA-100 CTs demonstrated a high specificity for adequate platelet function and, therefore, could be beneficial in improved transfusion of platelet concentrates or might help identify postoperative platelet hyperreactivity associated with myocardial lesion.

In conclusion, there appears on the surface to be some contradictory findings in terms of utility of the PFA-100 in the setting of surgical bleeding. One the one hand, several studies have been performed in the context of cardiac surgery with differential conclusions drawn. On the other hand, a large prospective study, which incorporated an evaluation of bleeding risk by patient survey, determined some significant value in the PFA100 detecting impaired hemostasis, both acquired and congenital, and of thus permitting targeted therapy that was able to reduce the frequency of blood transfusion. ${ }^{67,78}$ In contrast, the series of reports in the setting of $\mathrm{CPB}$ provided more modest conclusions, with some advocating its potential utility and others not. To some extent, the relative findings might be influenced by the study design and study end points. The PFA-100 CT is sensitive to hemodilution, so this will negate the utility of an abnormal PFA-100 CT in this setting. It is also important to consider that bleeding within surgery is dependent on both the patient's hemostatic status and the success of the surgery itself. A PFA-100 CT will not 
predict a bad surgical outcome due to surgical error. This author believes that there is little value in performing PFA-100 CTs on presurgical patients without a formal preoperative assessment of family and personal history of bleeding.

\section{ROLE OF THE PFA-100 IN MONITORING OF ANTIPLATELET THERAPY}

The PFA-100 has been used in studies investigating the effects, or therapeutic monitoring, of many compounds in addition to aspirin (see Table 1) and including antiglycoprotein (GP) IIb/IIIa agents such as abciximab, ${ }^{45,97-101}$ a multitude of nonsteroidal anti-inflammatory drugs (NSAIDs) such as meloxicam and indomethacin, ${ }^{102,103}$ and other antiplatelet compounds such as ticlopidine. ${ }^{45,104,105}$ The detailed findings of these studies are beyond the scope of this report. It is, however, important to recognize that (i) the PFA-100 CT can be affected by many such drugs; (ii) the PFA-100 CT is differentially affected by different drugs; (iii) the PFA-100 CT may have better utility for monitoring such therapy compared with classic SBT; (iv) drug effects may be dose related and potentially synergistic and may further depend on the citrate anticoagulant concentration used for blood collection; and (v) drug-related effects on CT may depend on the PFA-100 test cartridge used. For aspirin therapy, the $\mathrm{C} / \mathrm{Epi} \mathrm{CT}$ tends to be prolonged, but the C/ADP CT is usually normal. Accordingly, when this differential CT pattern is observed, it is sometimes touted as potential evidence of recent drug (e.g., aspirin) intake. There is a potential danger in doing this, as such a pattern can also reflect a significant primary hemostatic disorder. Nevertheless, recent medication should always be considered a potential cause of a prolonged CT (but in combination with other potential explanations), particularly if CT prolongation is only observed with the $\mathrm{C} /$ Epi cartridge.

\section{Sensitivity of the PFA-100 to Aspirin: Aspirin "Resistance," "Responsiveness," or "Nonresponsiveness"?}

There have been numerous studies to date on the potential utility of the PFA-100 in monitoring aspirin therapy. A new language is also emerging. Researchers have begun in earnest to talk about "aspirin resistance," "aspirin responsiveness," "aspirin nonresponsiveness," and even "pseudo-aspirin resistance." The big question is, can we use the PFA-100 to assess the potential "treatment failure" of aspirin therapy as reflected by this terminology? The prevailing view is that translation from research to clinical practice is perhaps premature, as reflected by the relevant International Society on Thrombosis and Haemostasis Scientific and Standard- ization Subcommittee (ISTH SSC) that was sufficiently concerned with this prospect to publish a recent note of caution. ${ }^{106}$ Its conclusion was that use of the PFA-100 $\mathrm{CT}$ "in therapeutic monitoring of platelet function is currently best restricted to research studies and prospective clinical trials."

Several reviews and meta-analyses on this subject have recently become available, ${ }^{23,107-109}$ which in turn have also resulted in some published correspondence and reevaluation of data. ${ }^{110-112}$ In brief, Crescente et $\mathrm{al}^{23}$ identified 73 publications that estimated aspirin response with the PFA-100. After exclusion of studies in which criterion for aspirin response was lacking, or where the number of aspirin responders could not be determined, or that reported duplicate data, or where aspirin was used in combination with other medications such as clopidogrel, the authors assessed that the pooled prevalence of nonresponders to aspirin as judged by PFA-100 testing, using 53 studies comprising 6450 subjects, had a median value of 0.27 . A higher number of aspirin nonresponders was found among older patients, those with acute vascular events, or those treated for more than 1 month. Aspirin nonresponse was more frequently associated with the use of local (in-house) cutoffs or when CT was only assessed after aspirin (rather than both before and after). Among risk factors, type 2 diabetes appeared to be associated with a higher prevalence of aspirin nonresponders. Nonresponse was also noted to be higher in less recent publications and in studies that used 3.2\% rather than $3.8 \%$ sodium citrate anticoagulant, hence the authors recommended 3.8\% citrate be used for future studies. Using pooled data from eight studies comprising 847 subjects, aspirin nonresponders were more likely to have vascular events than were responders (relative risk [RR], 1.63; 95\% confidence interval $[\mathrm{CI}], 1.16$ to 2.28 ). The authors concluded that although there appeared to be heterogeneity among the studies analyzed, about one quarter of people receiving aspirin would be identified on average as aspirin nonresponders by the PFA-100. They also advised that concerted efforts to better standardize studies and to control for major methodological variables would be required to improve monitoring of platelet performance under aspirin treatment and to firmly establish the observed association with clinical vascular events. With regard to the former comment, it was noted for example that study PFA$100 \mathrm{C} /$ Epi CT cutoff values varied from between 137 and 300 seconds, with about half the studies defining the cutoff as the upper limit of the normal distribution for their own healthy control group obtained in the absence of aspirin, and the remaining studies using a cutoff either established by a previous study or by the PFA-100 manufacturer.

Another major review was reported by Reny et al, ${ }^{107}$ who investigated the potential utility of the 
PFA-100 CT to predict cardiovascular events in aspirin-treated cardiovascular patients. Study selection criteria permitted incorporation of data from seven nonprospective studies (1466 patients) and eight prospective studies (1227 patients). A publication bias was identified in nonprospective studies. In prospective studies, the global odds ratio (OR) for the recurrence of an ischemic event in "aspirin nonresponders" relative to "aspirin responders" was 2.1 (95\% CI, 1.4 to 3.4; $p<0.001)$. The authors concluded that a short PFA$100 \mathrm{CT}$ for the $\mathrm{C} /$ Epi test cartridge was associated with increased recurrence of ischemic events in aspirintreated cardiovascular patients but that this finding required confirmation in stable ischemic patients and that PFA-100 CT cutoff values needed to be appropriately refined in these patients and in future studies.

The group of Crescente et al later refined their original study data ${ }^{23}$ in light of the findings of Reny et $\mathrm{al}^{107}$ and other groups ${ }^{108,109}$ to permit an analysis of 19 studies included in at least one of these four metaanalyses and that reported data on the association between "aspirin resistance/nonresponse" as assessed by the PFA-100 and clinical outcomes. A significantly higher risk of events was confirmed in aspirin "nonresponders" (OR, 2.35; 95\% CI, 1.96 to 2.83 ) compared with that in "responders." Nonprospective studies were found to report a higher risk of vascular events, probably because of their design, and this could overestimate the potential predictive value of PFA-100 in aspirin-treated patients. Dual antiplatelet therapy did not appear to reduce the risk of vascular events in subjects identified as "aspirin nonresponders" by the PFA-100. Interestingly, no significant difference was found between studies that used "low" or "high" PFA-100 CT cutoff values. They concluded that the significant association between "aspirin nonresponse" by platelet laboratory tests and the occurrence of vascular events, independently reported in four separate systematic reviews and meta-analyses ${ }^{23,107-109}$ and confirmed by the subsequent larger analysis, ${ }^{112}$ highlights the need for "prospective trials to firmly establish whether laboratory platelet tests and, in particular, readily available, simple point-of-care devices, such as PFA-100, are indeed useful to predict adverse vascular events and to optimize antiplatelet therapy. A better standardization of the test is also required before drawing any definite conclusions."

To summarize: With respect to current clinical practice, the existing evidence therefore suggests that it is still premature to use the PFA-100 to assess for aspirin responsiveness, aspirin nonresponsiveness, aspirin resistance, or treatment failure or to stratify such patients to increased or alternate medication. Nevertheless, the evidence also suggests that prospective studies using appropriate study refinements and better standardization may permit such use in the future. Within clinical practice, it is also very important to ensure patient compliance (i.e., to make sure that patients are actually taking medication as prescribed).

\section{Sensitivity of the PFA-100 to Clopidogrel}

One of the other medications of some significant interest within the PFA-100 story is clopidogrel. The PFA-100 appears to be only mildly sensitive to clopidogrel, ${ }^{99,113-}$ ${ }^{129}$ although several studies have shown clopidogrel to potentiate the effects of aspirin or other drugs on the PFA-100 CT and/or time dependence for clopidogrel sensitivity.

\section{IS THERE CLINICAL UTILITY OF THE PFA-100 FOR ANYTHING ELSE?}

At the start of this article, I identified that the PFA-100 had to date been featured in nearly 500 publications and some 35 reviews. I also noted that this review was not meant to be an exhaustive synopsis of all the literature related to the PFA-100 but rather would focus on several major clinical applications, summarized largely in Table 1. Nevertheless, it is worth highlighting a few of these other potential applications.

Some of the more interesting "nonmedication" compounds investigated for any effect on the PFA-100 $\mathrm{CT}$ include alcohol, ${ }^{130}$ cocoa/chocolate, ${ }^{131,132}$ garlic, ${ }^{133,134}$ and a range of herbal "medicines" including Ginkgo biloba, Asian ginseng, St. John's wort, saw palmetto, Ganoderma lucidum, and pycnogenol. ${ }^{134-136}$ Variable effects have been observed, with most producing little or no effect on the PFA-100 CT. Both alcohol and cocoa/chocolate consumption was found to prolong PFA-100 CTs, ${ }^{130-132}$ and this is an interesting finding given the trend for research to suggest that both alcohol and cocoa/chocolate may be somewhat protective against cardiovascular disease. ${ }^{137,138}$

The PFA-100 has also been evaluated within the context of various disease states other than VWD, platelet dysfunction, and thrombosis risk related to socalled aspirin resistance. For example, the PFA-100 has been assessed as a tool within the context of preeclampsia in pregnancy, ${ }^{139-141}$ where CTs were generally prolonged, but possibly secondary to lowered platelet count in this condition. The PFA-100 has also been assessed within the context of potential effects of air pollution on $\mathrm{CT}$ values, which tend to shorten in experimental models after exposure to pollutants. ${ }^{142-146} \mathrm{It}$ is not clear if this shortening reflects a platelet activation event or alternatively may reflect an effect that leads to increasing plasma VWF. The PFA-100 has also been evaluated in the context of renal and liver disease, ${ }^{147-149}$ where abnormal CTs can be observed, and in thyroid disease, where up to $3 \%$ of patients undergoing thyroid surgery have coagulation abnormalities, in most cases resembling VWD. ${ }^{79}$ 


\section{DO SHORT PFA-100 CT VALUES PER SE REFLECT INCREASED THROMBOSIS RISK?}

The potential for the PFA-100 to identify patients at potential risk of thrombosis related to so-called aspirin resistance has already been mentioned. Not only are relatively short $\mathrm{C} / \mathrm{Epi} \mathrm{CT}$ s a noted feature of so-called aspirin resistance, but also relatively short $\mathrm{C} / \mathrm{ADP} \mathrm{CT}$ s are consistently identified in these patients. However, this raises a bigger question of whether shortened PFA100 CTs per se might also reflect a prothrombotic tendency, and this research question is ripe for investigation.

Current research data linking shortened CTs to thrombotic risk is limited but also rapidly expanding. Frossard et $\mathrm{al}^{150}$ noted in 2004 that patients with STsegment-elevation myocardial infarction had significantly enhanced "platelet function" as detected by a relative reduction in $\mathrm{C} / \mathrm{ADP} \mathrm{CT}$, which they further identified as an independent predictor of the severity of myocardial infarction (MI), as measured by markers of cardiac necrosis. They predicted that the PFA-100 might help in the risk stratification of patients presenting with MI. Hertfelder et $\mathrm{al}^{96}$ reported elevated "plateletdependent primary hemostatic capacity" in patients with postoperative myocardial ischemia as identified by significantly shorter postoperative C/ADP CT compared with that in uncomplicated patients.

Sestito et $\mathrm{al}^{151}$ evaluated whether "platelet aggregability" was increased in patients with unstable angina (UA). They investigated 37 patients with UA, collected on admission to the coronary care unit, and 37 sex- and age-matched patients with chronic stable angina (CSA). CT was significantly reduced in UA patients compared with that in CSA patients. Among UA patients, serum C-reactive protein (CRP) levels had a median value of $5.1 \mathrm{mg} / \mathrm{L}$ (bottom and top quartile levels, 1.50 to 7.95$)$. There was no significant correlation between closure time and CRP levels $(r=0.22$, $p=0.29)$. They concluded that in patients with UA, there was an increase of "platelet reactivity" as measurable by $\mathrm{C} / \mathrm{ADP}$ stimulation, which was not related to inflammation.

Yee et $\mathrm{al}^{152}$ studied in a large group of subjects $(n=386)$ to assess the relationship between healthy individuals' "platelet reactivity" to epinephrine and their platelet phenotype as measured by various functional assays. Subjects with hyperreactivity to epinephrine were more likely to exhibit hyperfunction in each major aspect of platelet activity, including adhesion (response to low-dose ristocetin), activation (surface $\mathrm{P}$-selectin expression and PAC-1 binding after stimulation), and aggregation to other agonists (no agonist, ADP, arachidonic acid, collagen, collagen-related peptide, and ristocetin) and to applied shear stress (PFA100 and cone-and-plate viscometer). These differences were found to persist after adjusting for demographic and hematologic differences between groups. They also studied candidate genes relevant to epinephrine-mediated platelet activation and found that hyperreactivity to epinephrine was associated with a polymorphism on the gene (GNB3) encoding the $\beta-3$ subunit of $G$ proteins. They concluded that "robust aggregation to a submaximal concentration of epinephrine" established a "true hyper-reactive platelet phenotype that is 'global' as opposed to agonist specific" and that "detection of this phenotype could be useful for studying patients at risk for arterial thrombosis."

Fuchs et $\mathrm{al}^{153}$ assessed whether "platelet hyperfunction" contributed to acute coronary syndromes (ACSs). They studied 208 consecutive ACS patients prospectively followed-up for an average of 28 months. PFA-100 CTs were performed for both C/ADP and C/ Epi at baseline and after infusion of a uniform dose of $250 \mathrm{mg}$ aspirin. Of the conventional risk factors, only the prevalence of diabetes was higher in ACS patients with re-events. Inclusion of $\mathrm{VWF}$ levels in a multivariant analysis reduced the hazard ratio for C/ADP CT. They concluded that shortened CT values reflected biologically relevant platelet "hyperfunction" in patients with ACS because they predicted recurrent ACS.

Giusti et $\mathrm{al}^{154}$ evaluated the effect of various platelet GPIa polymorphisms on modulating platelet function in MI patients on dual antiplatelet treatment undergoing percutaneous coronary intervention (PCI). They measured platelet function by both PFA-100 and platelet-rich plasma aggregation in $289 \mathrm{MI}$ patients undergoing PCI and receiving dual antiplatelet treatment. Their data showed that certain polymorphisms, but not all, were associated with higher platelet reactivity.

Linden et $\mathrm{al}^{155}$ aimed to determine whether indices of platelet activation were associated with the stability of coronary artery disease (CAD). They performed PFA-100 CTs on 677 consecutive aspirintreated patients presenting for cardiac catheterization. Patients were grouped into recent $\mathrm{MI}$, no $\mathrm{MI}$ but angiographically documented CAD (non-MI CAD), and no angiographically detectible CAD (no CAD), as well as additional subgroups. Compared with non-MI $\mathrm{CAD}$ or no CAD patients, more patients with recent $\mathrm{MI}$ had a shortened $\mathrm{C} / \mathrm{Epi} \mathrm{CT}$ and increased circulating monocyte-platelet aggregates, neutrophil-platelet aggregates, and activated platelet surface GPIIb-IIIa and plasma-soluble CD40 ligand (sCD40L). More patients with non-MI CAD had shortened PFA-100 CTs and increased monocyte-platelet aggregates compared with that in patients with no CAD. Platelet surface P-selectin did not differ among the groups. Subgroup analysis revealed that decreasing PFA-100 CT correlated with the stability of CAD. They concluded that the PFA-100 CT was associated with the stability of CAD and might reflect plaque instability, an ongoing thrombotic state, and/or reduced responsiveness to aspirin. 
Serebruany et $\mathrm{al}^{156}$ investigated whether evidence could be found for an association of the metabolic syndrome with risk for vessel occlusion. They assessed "platelet activity" by conventional aggregation, expression of major surface receptors by flow cytometry, and by PFA-100 CT in 20 aspirin-naïve patients with documented metabolic syndrome and compared these with 20 untreated subjects with multiple cardiovascular risk factors. PFA-100 CTs were significantly shorter in patients with metabolic syndrome. Ultegra (Accumetrics, Inc, San Diego, CA) analyzer readings revealed increased fibrinogen binding, and flow cytometry revealed an increased expression of PAC-1, strongly suggesting activation of the platelet GPIIb/IIIa receptor. Surface expression of other activation markers were also higher in patients with metabolic syndrome. In contrast, platelet aggregation induced by collagen or ADP, and expression of other markers (CD31, CD41, CD42b, CD51/61, CD62p, CD63, CD154, CD165), formation of platelet-monocyte aggregates, protease-activated receptor 1 (PAR-1) thrombin receptor, and thrombospondin did not differ between groups. They concluded that patients with metabolic syndrome exhibited a higher degree of platelet activation than did subjects with conventional risk factors for vascular disease.

Jacopo et $\mathrm{al}^{157}$ investigated "platelet hyperreactivity" as a possible risk factor for recurrent myocardial ischemia and in-stent thrombosis after PCI using C/Epi CT measurements in 256 consecutive patients with stable angina $(n=103)$ or ACS $(n=153) 30 \pm 8$ hours after PCI (T 0) and 1 month later (T1). All patients were followed for a mean period of 9 months. Baseline C/Epi $\mathrm{CT}<190$ seconds was associated with a higher rate of death or MI compared with C/Epi CT $>190$ seconds. Multivariable analysis after adjustment for other risk factors confirmed that baseline C/Epi CT $<190$ seconds was an independent correlate for death or MI (hazard ratio $6.981 ; p=0.008)$. They concluded that a $\mathrm{C} / \mathrm{Epi}$ $\mathrm{CT}<190$ seconds measured within the first 24 hours after PCI predicted in-stent thrombosis defined as the occurrence of death or MI.

Jilma-Stohlawetz et $\mathrm{al}^{158}$ attempted to identify whether platelet polymorphisms of GPIb- $\alpha$ contributed to the risk of thromboembolic disease in patients with lupus anticoagulants (LA) and a history of thromboembolism $(\mathrm{LA} / \mathrm{TE}+)$ versus those with LA but without TE (LA/TE-). The C/Epi CT of the PFA-100 was shorter in LA/TE + than in LA/TE $-(p=0.044)$, but this difference did not persist after exclusion of patients with low platelet counts or low ristocetin cofactor activity. The Kozak dimorphism they evaluated was not found to have any discernible effect on the PFA-100 CT.

Harrison et $\mathrm{al}^{159}$ assessed the potential utility of the PFA-100 to identify "platelet hyperfunction" using 78 patients presenting with acute chest pain. Patients were classified into MI, unstable angina (UA), and nonspecific chest pain. All patients received $300 \mathrm{mg}$ aspirin (ASA) more than 2 hours before blood samples were collected. Twenty healthy normal subjects were also tested before and 2 hours after $300 \mathrm{mg}$ ASA. The C/ ADP CT was significantly shorter in MI patients but not in UA patients compared with that in normal subjects. The C/Epi CTs were significantly longer in UA patients than in untreated controls (as expected), but there was no difference in MI patients, suggesting that the MI patients were not all responding to ASA. Analysis of a subset of the apparent ASA nonresponders $(n=5)$ by platelet aggregation demonstrated that this was not related to failure of ASA to block cyclooxygenase activity. Interestingly, VWF levels were significantly elevated in both UA and MI patients compared with that in normal subjects and were also significantly higher in the MI group compared with that in the UA group. They concluded that there was evidence for platelet hyperfunction and elevated VWF levels in the MI group that could explain their decreased responsiveness to aspirin using the $\mathrm{C} /$ Epi cartridge.

Some of the above-noted studies help to remind us that the PFA-100 is a global test of "platelet function" and that platelet count, structure, and activity together with VWF level, structure, and activity will influence CTs. Thus, the PFA-100 is generally sensitive to aspirin effects (prolongs $\mathrm{CT}$ with $\mathrm{C} / \mathrm{Epi}$ ) as well as to plasma VWF (significant deficiencies will prolong both $\mathrm{C} / \mathrm{Epi}$ and $\mathrm{C} / \mathrm{ADP}$ ). It is well recognized that lowered VWF representing VWD will lead to prolongation of PFA-100 CTs and a bleeding diathesis. What is less well appreciated is that elevated plasma VWF will lead to shortening of PFA-100 CTs ${ }^{76}$ and that elevated VWF is also a risk factor for thrombosis. ${ }^{160,161}$ Moreover, plasma VWF will moderate PFA-100 CTs for individuals on aspirin therapy, ${ }^{159,162}$ and will thus influence the perception of aspirin resistance. ${ }^{163}$ Thrombosis, like a bleeding diathesis, is potentially influenced by many factors. We should no longer consider an increased risk of either thrombosis or a bleeding diathesis as single-event phenomena. Future prospective studies investigating thrombosis risk and the phenomenon of aspirin resistance should incorporate evaluation of plasma VWF using activity-based assays such as the VWF:CB in addition to VWF:Ag. ${ }^{164,165}$

Perhaps we should raise the analogy here of the APTT and secondary hemostasis. In the past, the APTT has been used as a screening test to primarily assess bleeding risk (i.e., elevated APTT suggesting loss of clotting factors). More recent interest, however, is in the potential utility of a short APTT to reflect thrombotic risk. ${ }^{166} \mathrm{~A}$ similar situation with respect to recognizing the potential for the PFA-100 in terms of a short CT as reflecting thrombotic risk appears to be just around the corner. 


\section{CONCLUSION}

In terms of the potential role of the PFA-100 as a screening tool for primary hemostasis, this author likens this role to that of the APTT as a screening tool for secondary hemostasis, both tests being mostly used for their high negative predictive value. Thus, for the PFA100 , good sensitivity is observed for VWD and for severe platelet dysfunction, but as the PFA-100 is also sensitive to medication events (in particular aspirin) and to lowered platelet count and hematocrit, the PFA-100 would have poor specificity for any particular disorder. Thus, a normal PFA-100 CT result (particularly for the $\mathrm{C} /$ Epi cartridge) can be used with some confidence to exclude severe VWD or severe platelet dysfunction but would not exclude a possible mild VWF deficiency or mild platelet disorder. Conversely, an abnormal PFA$100 \mathrm{CT}$ will not necessarily define a primary hemostatic disorder, as one would also need to exclude a medication effect, or lowered platelet count and hematocrit. In other words, the PFA-100 is a screening tool and should not prevent the performance of the proper diagnostic assays when evaluating patients for a primary hemostatic disorder. These specific assays would comprise VWF assays for addressing the clinical suspicion of VWD, and classic platelet function assays for addressing the clinical suspicion of platelet dysfunction.

This is similar to the situation for the APTT and secondary hemostasis. A normal APTT result can be used with some confidence to exclude a severe factor deficiency (e.g., factors VIII, IX, and XI) and thus severe hemophilia but would not exclude a possible mild factor deficiency. Conversely, an abnormal APTT will not necessarily define a secondary hemostatic disorder, as one would also need to exclude a preanalytical event, ${ }^{21}$ a medication effect (e.g., heparin, vitamin $\mathrm{K}$ antagonist therapy such as warfarin), ${ }^{21}$ a less clinically significant factor deficiency (e.g., XII), or a possible LA (feasibly from an asymptomatic patient). In other words, the APTT is also a screening tool, and performance of an APTT should not prevent the performance of the proper diagnostic assays when evaluating patients for a secondary hemostatic disorder. Just as the APTT has no value in screening otherwise unselected preoperative cases, ${ }^{167,168}$ the PFA-100 also has no value in screening otherwise unselected preoperative cases. ${ }^{167}$ This is simply due to the lack of $100 \%$ sensitivity and specificity of each of APTT and PFA-100 for secondary and primary hemostasis, respectively. These specific assays would comprise VWF assays for addressing the clinical suspicion of VWD, and classic platelet function assays for addressing the clinical suspicion of platelet dysfunction.

When appropriately applied (i.e., used selectively, and after exclusion of acquired defects related to medication or lowered platelet count or hematocrit, and in the case of patients with a positive family and/or personal history of bleeding), the PFA-100 has some clinical utility in detection of primary hemostatic disorders. ${ }^{15-}$ 18,67 However, this clinical utility is diluted if poorly applied. Analogously, the APTT, used selectively, and after exclusion of acquired defects related to medication or LA, and in the case of patients with a positive family and/or personal history of bleeding, would similarly have some value in detection of secondary hemostatic disorders. A recommended algorithm for use of the PFA-100 in screening hemostatic disturbances has been provided by this author in several previous reviews and has been updated as Fig. 2.

In addition, the PFA-100 is also sensitive to hemostatic changes induced by DDAVP therapy in appropriately responding individuals (both for VWD and platelet disorders). Accordingly, the PFA-100 also has a role in the monitoring of therapeutic support in these circumstances. ${ }^{15,16,18,83,84}$

There are some other points worth briefly revisiting. There are noted differences in the relative sensitivity of the two PFA-100 cartridges, with the C/Epi cartridge showing the greatest sensitivity to hemostatic disturbances, including those related to VWD, or platelet dysfunction, or medication/therapy. However, despite this higher sensitivity, it is also accordingly clear that the $\mathrm{C} / \mathrm{Epi}$ cartridge shows the least specificity for VWD or any other specific hemostatic disorder (i.e., greater effects are more persistently observed, or CT more prolonged, in the case of VWD, thrombocytopenia, platelet dysfunction, or due to medication). The anticipated dual test pattern (C/Epi and C/ADP CTs) and its reflection on possible explanatory scenarios is provided in Fig. 3.

In usual practice, there is no need to perform a $\mathrm{C} / \mathrm{ADP} \mathrm{CT}$ if the C/Epi CT is normal, as the C/ADP can be predicted in $>99 \%$ of test cases to also be normal. Duplicate testing is also not usually required, although it may be selectively applied. The original report by Mammen et $\mathrm{al}^{3}$ indicated a within-day CV of $<10 \%$, and other workers have also reported on good reproducibility, provided that samples are collected under ideal conditions and following the best standards of practice. ${ }^{11,22,25,61,169}$ However, some researchers have observed higher test imprecision, and on occasion, individual duplicate readings can vary by much more than $10 \%$; furthermore, precision may be worse when assessing samples from patients on aspirin. ${ }^{170-172}$ Hence, some workers recommend duplicate readings. In our own experience, duplicates can on occasion vary by up to $20 \%$ but rarely more than this (unpublished findings from the author). Accordingly, our practice is to perform duplicates only when CT values are close to cutoff values or when results are strongly in variance with expectations based on history or family studies. For example, there is little point in repeating a C/Epi CT of say 100 seconds or of $>250$ seconds; the former is clearly normal and the latter clearly abnormal. In the case of the former, a repeat within $20 \%$ will still be normal, and for the latter a repeat 


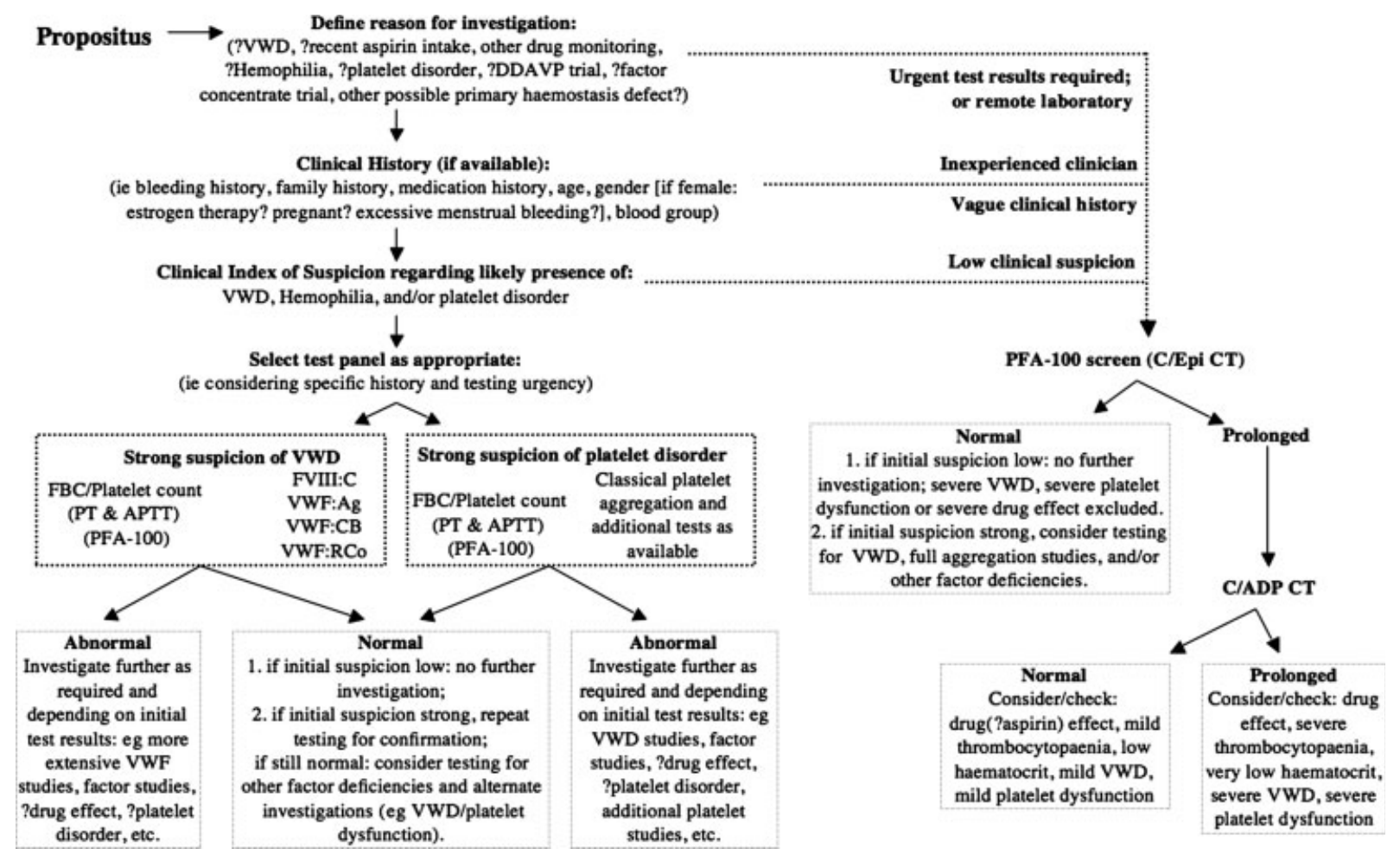

Figure 2 An algorithm that reflects one possible approach to the investigation of individuals with potential VWD or other primary hemostatic or platelet disturbances when using the PFA-100.

within $20 \%$ will still be abnormal. In the case of the latter, testing with the C/ADP cartridge would be of more value to determine whether the overall test pattern would differentially support a medication effect/mild disorder versus a severe disorder. In addition, a full blood count is mandatory for all PFA-100 testing to assess potential hematocrit or low platelet count events.

Finally, the evaluation of the PFA-100 in terms of assessing thrombosis risk is also gathering momentum, and relatively short $\mathrm{CT}$ values appear to predict thrombosis risk in some settings, inclusive of patients undergoing antiplatelet therapy or otherwise.

Ultimately, the greatest strengths of the PFA-100 are its simplicity and excellent sensitivity to particular hemostatic disturbances such as VWD, platelet disorders, and platelet-affecting medication. This high sensitivity is both its greatest strength and biggest limitation. With regard to the former, high sensitivity to all these parameters makes the PFA-100 a useful screening tool for the identification (and therapeutic monitoring) of VWD, platelet dysfunction, and antiplatelet medication. With regard to the latter, such high sensitivity for multiple parameters means that the PFA-100 has poor specificity for any particular parameter and is nondiagnostic.

In our own laboratory, the PFA-100 with regard to identification of severe VWD and platelet dysfunction is used in acute needs (e.g., preoperative, prolonged APTT, vague history, normal factor VIII coagulant
[FVIII:C]), and primarily as a negative screening tool. Thus, a normal PFA-100 will generally discount severe VWD and severe platelet dysfunction. However, a normal PFA-100 will not discount "mild" deficiencies in VWF or "mild" platelet dysfunction. Moreover, a prolonged PFA-100 CT is nondiagnostic and does not define any particular disorder or whether a disorder of primary hemostasis in fact exists. A prolonged CT might indicate VWD, or platelet dysfunction, or thrombocytopenia, or low hematocrit, or may represent an antiplatelet medication effect. A prolonged CT will generally require some follow-up, the extent of which is case dependent. In a case with weak history, a fullblood count and full medication review is required to assess thrombocytopenia, low hematocrit, or antiplatelet medication. In a case with significant bleeding history, specific VWD studies and possibly comprehensive platelet function testing would be additionally indicated after exclusion of thrombocytopenia, low hematocrit, or antiplatelet medication.

\section{Future Considerations}

The PFA-100 has remained unchanged for the past 10 to 15 years, and it is now time for an overhaul. The manufacturer should give consideration to the following:

1. Improving sensitivity to factor replacement therapy in VWD treatment. This might be accomplished by 


\section{C/Epi CT}

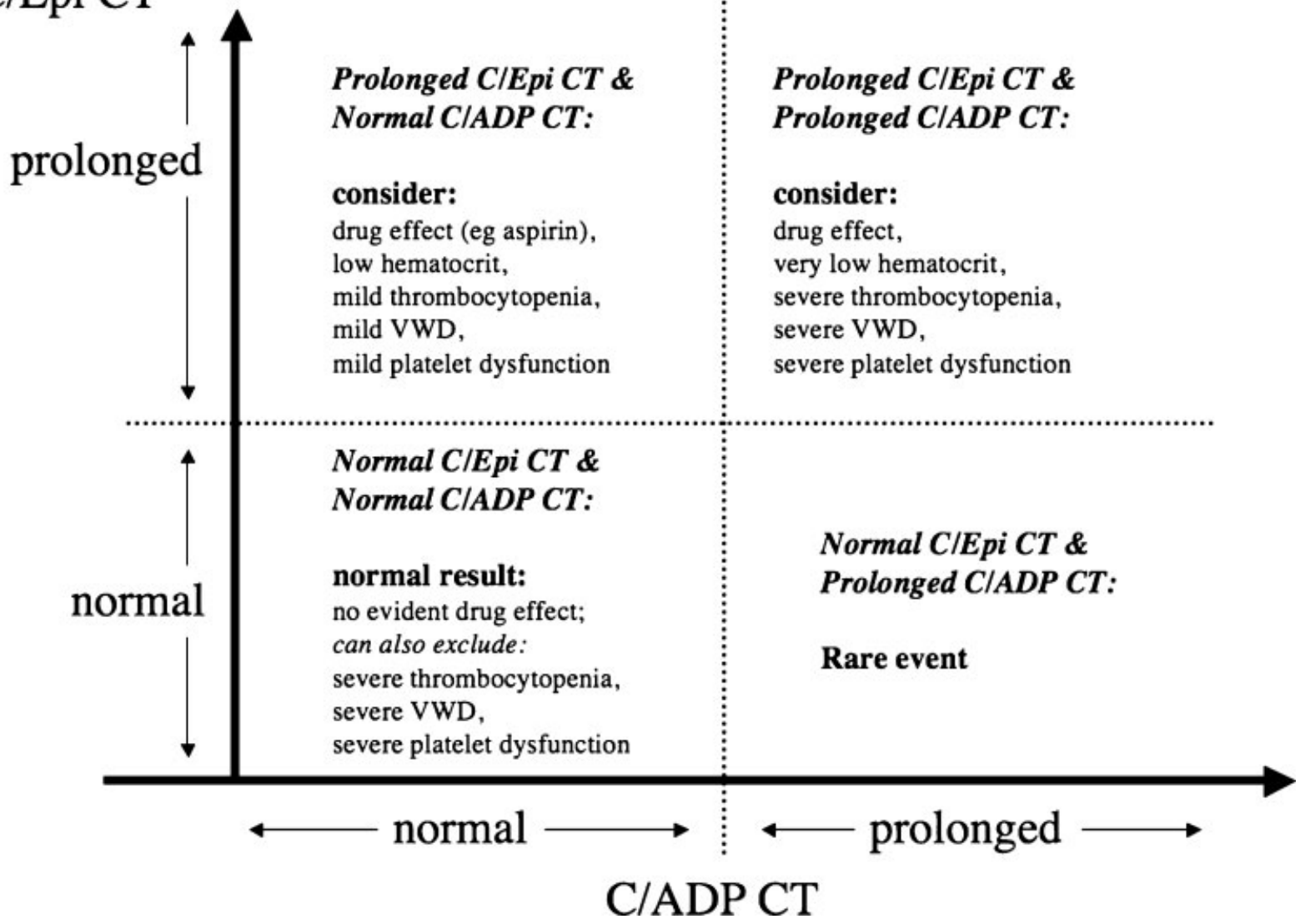

Figure 3 Simple representation of likely clinical scenarios suggested by PFA-100 CT results using both C/ADP and C/Epi cartridges.

extending the CT to greater than the current limits of 300 seconds (which may require an allowance for a greater volume of blood for testing purposes) or preferably by an operator-dependent mechanism to enable one to reduce shear and hence blood flow to permit finer data collection). ${ }^{18,84}$

2. Extending the range of cartridge types available to better identify a broader range of platelet function defects. ${ }^{18}$

3. Improving its utility for assessing primary hemostasis function in thrombocytopenic patients or those with a low hematocrit. ${ }^{18,173,174}$

\section{The Final Word on the PFA-100 Story}

Perhaps it is fitting to end this article where we began and to allow Eberhard Mammen to have the last word on this topic. In closing his 1998 article in Seminars in Thrombosis and Hemostasis, he identified the PFA-100 as "an excellent test system to assess platelet-related primary hemostasis with high accuracy and reliability ...," that ". . . may be effectively utilized as a routine test to detect abnormal platelet function ..." and further that "the ease with which the PFA-100 system can be operated makes it an excellent tool to screen for plate- let-related primary hemostasis defects.” But perhaps even Eberhard could not predict how far the interest in the PFA-100 would grow.

\section{REFERENCES}

1. Alshameeri RS, Mammen EF. Clinical experience with the Thrombostat 4000. Semin Thromb Hemost 1995; 21(Suppl 2):1-10

2. Kundu SK, Heilmann EJ, Sio R, Garcia C, Davidson RM, Ostgaard RA. Description of an in vitro platelet function analyzer-PFA-100. Semin Thromb Hemost 1995;21 (Suppl 2):106-112

3. Mammen EF, Alshameeri RS, Comp PC. Preliminary data from a field trial of the PFA-100 system. Semin Thromb Hemost 1995;21(Suppl 2):113-121

4. Kundu SK, Heilmann EJ, Sio R, Garcia C, Ostgaard RA. Characterisation of an in-vitro Platelet Function Analyser, PFA-100 ${ }^{\circledR}$. Clin Appl Thromb Hemost 1996; 2:241-249

5. Heilmann EJ, Kundu SK, Sio R, Garcia C, Gomez R, Christie DJ. Comparison of four commercial citrate blood collection systems for platelet function analysis by the PFA-100 system. Thromb Res 1997;87:159-164

6. Marshall PW, Williams AJ, Dixon RM, et al. A comparison of the effects of aspirin on bleeding time measured using the Simplate method and closure 
time measured using the PFA-100, in healthy volunteers. Br J Clin Pharmacol 1997;44: 151-155

7. Fressinaud E, Veyradier A, Truchaud F, et al. Screening for von Willebrand disease with a new analyzer using high shear stress: a study of 60 cases. Blood 1998;91:1325-1331

8. Mammen EF, Comp PC, Gosselin R, et al. PFA-100 system: a new method for assessment of platelet dysfunction. Semin Thromb Hemost 1998;24:195-202

9. Carcao MD, Blanchette VS, Dean JA, et al. The Platelet Function Analyzer (PFA-100): a novel in-vitro system for evaluation of primary haemostasis in children. $\mathrm{Br} \mathrm{J}$ Haematol 1998;101:70-73

10. Knöfler R, Weissbach G, Kuhlisch E. Platelet function tests in childhood. Measuring aggregation and release reaction in whole blood. Semin Thromb Hemost 1998;24:513-521

11. Rand ML, Carcao MD, Blanchette VS. Use of the PFA100 in the assessment of primary, platelet-related hemostasis in a pediatric setting. Semin Thromb Hemost 1998;24:523529

12. Suzuki S, Morishita S. Platelet hemostatic capacity (PHC) and fibrinolytic inhibitors during pregnancy. Semin Thromb Hemost 1998;24:449-451

13. Keidel A, Mischke R. Clinical evaluation of platelet function analyzer PFA-100 in dogs. Berl Munch Tierarztl Wochenschr 1998;111:452-456

14. Nicholson NS, Panzer-Knodle SG, Haas NF, et al. Assessment of platelet function assays. Am Heart J 1998;135:S170S178

15. Favaloro EJ. Utility of the PFA $-100^{\circledR}$ for assessing bleeding disorders and monitoring therapy: a review of analytical variables, benefits and limitations. Haemophilia 2001;7: 170-179

16. Favaloro EJ. Clinical application of the PFA- $100^{\circledR}$. Curr Opin Hematol 2002;9:407-415

17. Favaloro EJ. The utility of the PFA-100 in identification of von Willebrand disease: a concise review. Semin Thromb Hemost 2006;32:537-545

18. Favaloro EJ. Laboratory monitoring of therapy in von Willebrand disease: efficacy of the PFA-100 ${ }^{\mathbb{R}}$ and VWF:CB as coupled strategies. Semin Thromb Hemost 2006;32:566-576

19. Favaloro EJ, Bonar R, Duncan E, Rodgers S, Marsden K(on behalf of the RCPA QAP in Haematology). The utility of the PFA $-100^{\mathbb{R}}$ as a screening test of platelet function: an audit of haemostasis laboratories in Australia and New Zealand. Blood Coagul Fibrinolysis 2007;18:441-448

20. Duncan EM, Bonar R, Rodgers SE, Favaloro EJ, Marsden K. Methodology and outcomes of platelet aggregation testing in Australia, New Zealand and the Asia-Pacific region: results of a survey from the Royal College of Pathologists of Australasia Haematology Quality Assurance Program. Int J Lab Hematol 2009; in press

21. Favaloro EJ, Lippi G, Adcock DM. Preanalytical and postanalytical variables: the leading causes of diagnostic error in haemostasis? Semin Thromb Hemost 2008;34:612634

22. Jilma B. Platelet function analyzer (PFA-100): a tool to quantify congenital or acquired platelet dysfunction. J Lab Clin Med 2001;138:152-163

23. Crescente M, Di Castelnuovo A, Iacoviello L, Vermylen J, Cerletti C, de Gaetano G. Response variability to aspirin as assessed by the platelet function analyzer (PFA)-100. A systematic review. Thromb Haemost 2008;99:14-26
24. Dyszkiewicz-Korpanty A, Quinton R, Yassine J, Sarode R. The effect of a pneumatic tube transport system on PFA100 closure time and whole blood platelet aggregation. J Thromb Haemost 2004;2:354-356

25. Bock M, De Haan J, Beck KH, et al. Standardization of the PFA-100(R) platelet function test in $105 \mathrm{mmol} / \mathrm{l}$ buffered citrate: effect of gender, smoking, and oral contraceptives. Br J Haematol 1999;106:898-904

26. Sestito A, Sciahbasi A, Landolfi R, Maseri A, Lanza GA, Andreotti F. A simple assay for platelet-mediated hemostasis in flowing whole blood (PFA-100): reproducibility and effects of sex and age. Cardiologia 1999;44:661-665

27. Cho YU, Chi HS, Jang S, Park CJ. Reconfirmation of preanalytical variables and establishment of reference intervals of platelet function analyzer-100 closure times in Korean adults. Korean J Lab Med 2007;27:318-323

28. Brockmann MA, Beythien C, Magens MM, Wilckens V, Kuehnl P, Gutensohn K. Platelet hemostasis capacity in smokers. In vitro function analyses with $3.2 \%$ citrated whole blood. Thromb Res 2001;104:333-342

29. Lippi G, Manzato F, Franchini M, Brocco G, Florenziani G, Guidi G. Establishment of reference values for the PFA100 platelet function analyzer in pediatrics. Clin Exp Med 2001;1:69-70

30. Suzuki S, Morishita S. The relationship between the onset of labor mechanisms and the hemostatic system. Immunopharmacology 1999;43:133-140

31. Davies JR, Fernando R, Hallworth SP. Hemostatic function in healthy pregnant and preeclamptic women: an assessment using the platelet function analyzer (PFA-100) and thromboelastography. Anesth Analg 2007;104:416-420

32. Vincelot A, Nathan N, Collet D, Mehaddi Y, Grandchamp $\mathrm{P}$, Julia A. Platelet function during pregnancy: an evaluation using the PFA-100 analyser. Br J Anaesth 2001;87:890-893

33. Marietta M, Castelli I, Piccinini F, et al. The PFA-100 system for the assessment of platelet function in normotensive and hypertensive pregnancies. Clin Lab Haematol 2001;23:131-134

34. Feuring M, Christ M, Roell A, et al. Alterations in platelet function during the ovarian cycle. Blood Coagul Fibrinolysis 2002;13:443-447

35. Lippi G, Franchini M, Brocco G, Manzato F. Influence of the ABO blood type on the platelet function analyzer PFA100. Thromb Haemost 2001;85:369-370

36. Jilma-Stohlawetz $\mathrm{P}$, Hergovich N, Homoncik M, et al. Impaired platelet function among platelet donors. Thromb Haemost 2001;86:880-886

37. Moeller A, Weippert-Kretschmer M, Prinz H, Kretschmer $\mathrm{V}$. Influence of ABO blood groups on primary hemostasis. Transfusion 2001;41:56-60

38. Feuring M, Harenberg J, Peiter A, et al. Impact of ABO blood groups on tirofiban mediated inhibition of platelet function. Platelets 2005;16:430-434

39. Welsby IJ, Jones R, Pylman J, et al. Cardiothoracic Anesthesiology Research Endeavours. (C.A.R.E.). Blood ABO blood group and bleeding after coronary artery bypass graft surgery. Blood Coagul Fibrinolysis 2007;18: 781-785

40. Dalby MC, Davidson SJ, Burman JF, Davies SW. Diurnal variation in platelet aggregation with the PFA-100 platelet function analyser. Platelets 2000;11:320-324

41. Pamukcu B, Oflaz H, Acar RD, et al. The role of exercise on platelet aggregation in patients with stable coronary 
artery disease: exercise induces aspirin resistant platelet activation. J Thromb Thrombolysis 2005;20:17-22

42. Lippi G, Montagnana M, Salvagno GL, Franchini M, Guidi GC. Comparison of platelet function between sedentary individuals and competitive athletes at rest. Thromb J 2006;4:10

43. Aurigemma C, Fattorossi A, Sestito A, et al. Relationship between changes in platelet reactivity and changes in platelet receptor expression induced by physical exercise. Thromb Res 2007;120:901-909

44. Nimmerfall K, Mischke R. Effect of unfractionated and low-molecular-weight heparin on platelet aggregation and in vitro bleeding time in dogs. Dtsch Tierarztl Wochenschr 1999;106:439-444

45. Kottke-Marchant K, Powers JB, Brooks L, Kundu S, Christie DJ. The effect of antiplatelet drugs, heparin, and preanalytical variables on platelet function detected by the platelet function analyzer (PFA-100). Clin Appl Thromb Hemost 1999;5:122-130

46. Homoncik M, Jilma B, Hergovich N, Stohlawetz P, Panzer S, Speiser W. Monitoring of aspirin (ASA) pharmacodynamics with the platelet function analyzer PFA-100. Thromb Haemost 2000;83:316-321

47. Ortel TL, James AH, Thames EH, Moore KD, Greenberg CS. Assessment of primary hemostasis by PFA-100 analysis in a tertiary care center. Thromb Haemost 2000;84:93-97

48. Rudnicka AR, Rumley A, Lowe GD, Strachan DP. Diurnal, seasonal, and blood-processing patterns in levels of circulating fibrinogen, fibrin D-dimer, C-reactive protein, tissue plasminogen activator, and von Willebrand factor in a 45-year-old population. Circulation 2007;115:996-1003

49. Fressinaud E, Veyradier A, Sigaud M, Boyer-Neumann C, Le Boterff C, Meyer D. Therapeutic monitoring of von Willebrand disease: interest and limits of a platelet function analyser at high shear rates. Br J Haematol 1999;106:777783

50. Cattaneo M, Federici AB, Lecchi A, et al. Evaluation of the PFA-100 system in the diagnosis and therapeutic monitoring of patients with von Willebrand disease. Thromb Haemost 1999;82:35-39

51. Favaloro EJ, Facey D, Henniker A. Use of a novel platelet function analyzer (PFA-100) with high sensitivity to disturbances in von Willebrand factor to screen for von Willebrand's disease and other disorders. Am J Hematol 1999;62:165-174

52. Meskal A, Vertessen F, Van der Planken M, Berneman ZN. The platelet function analyzer (PFA-100) may not be suitable for monitoring the therapeutic efficiency of von Willebrand concentrate in type III von Willebrand disease. Ann Hematol 1999;78:426-430

53. Kerenyi A, Schlammadinger A, Ajzner E, et al. Comparison of PFA-100 closure time and template bleeding time of patients with inherited disorders causing defective platelet function. Thromb Res 1999;96:487-492

54. Harrison P, Robinson MS, Mackie IJ, et al. Performance of the platelet function analyser PFA-100 in testing abnormalities of primary haemostasis. Blood Coagul Fibrinolysis 1999;10:25-31

55. Dean JA, Blanchette VS, Carcao MD, et al. von Willebrand disease in a paediatric-based population-comparison of type 1 diagnostic criteria and use of the PFA $-100^{\circledR}$ and a von Willebrand factor/collagen-bindiing assay. Thromb Haemost 2000;84:401-409
56. Schlammadinger A, Kerenyi A, Muszbek L, Boda Z. Comparison of the O'Brien filter test and the PFA-100 platelet analyser in the laboratory diagnosis of von Willebrands disease. Thromb Haemost 2000;84:88-92

57. Ortel TL, James AH, Thames EH, Moore KD, Greenberg CS. Assessment of primary hemostasis by PFA-100 analysis in a tertiary care center. Thromb Haemost 2000;84:93-97

58. Favaloro EJ, Kershaw G, Bukuya M, Hertzberg M, Koutts J. Laboratory diagnosis of von Willebrand disorder (VWD) and monitoring of DDAVP therapy: efficacy of the PFA-100 ${ }^{\mathbb{R}}$ and VWF:CBA as combined diagnostic strategies. Haemophilia 2001;7:180-189

59. Harrison P, Robinson M, Liesner R, et al. The PFA-100: a potential rapid screening tool for the assessment of platelet dysfunction. Clin Lab Haematol 2002;24:225-232

60. Buyukasik Y, Karakus S, Goker H, et al. Rational use of the PFA-100 device for screening of platelet function disorders and von Willebrand disease. Blood Coagul Fibrinolysis 2002;13:349-353

61. Wuillemin WA, Gasser KM, Zeerleder SS, Lämmle B. Evaluation of a Platelet Function Analyser (PFA-100) in patients with a bleeding tendency. Swiss Med Wkly 2002; 132:443-448

62. Nitu-Whalley IC, Lee CA, Brown SA, Riddell A, Hermans C. The role of the platelet function analyser (PFA-100) in the characterization of patients with von Willebrand's disease and its relationships with von Willebrand factor and the ABO blood group. Haemophilia 2003;9:298-302

63. Cariappa R, Wilhite TR, Parvin CA, Luchtman-Jones L. Comparison of PFA-100 and bleeding time testing in pediatric patients with suspected hemorrhagic problems. J Pediatr Hematol Oncol 2003;25:474-479

64. Posan E, McBane RD, Grill DE, Motsko CL, Nichols WL. Comparison of PFA-100 testing and bleeding time for detecting platelet hypofunction and von Willebrand disease in clinical practice. Thromb Haemost 2003;90:483-490

65. Favaloro EJ. Template bleeding time and PFA-100 have low sensitivity to screen patients with hereditary mucocutaneous hemorrhages: comparative study of 148 patients-a rebuttal. J Thromb Haemost 2004;2:2280-2282

66. Quiroga T, Goycoolea M, Muñoz B, et al. Template bleeding time and PFA-100 have low sensitivity to screen patients with hereditary mucocutaneous hemorrhages: comparative study in 148 patients. Thromb Haemost 2004;2:892-898

67. Koscielny J, Ziemer S, Radtke H, et al. A practical concept for preoperative identification of patients with impaired primary hemostasis. Clin Appl Thromb Hemost 2004;10: 195-204

68. Philipp CS, Miller CH, Faiz A, et al. Screening women with menorrhagia for underlying bleeding disorders: the utility of the platelet function analyser and bleeding time. Haemophilia 2005;11:497-503

69. Penas N, Pérez-Rodríguez A, Torea JH, et al. Willebrand disease R1374C: type $2 \mathrm{~A}$ or $2 \mathrm{M}$ ? A challenge to the revised classification. High frequency in the northwest of Spain (Galicia) Am J Hematol 2005;80:188-196

70. Favaloro EJ, Lloyd J, Rowell J, et al. Comparison of the pharmacokinetics of two von Willebrand factor concentrates [Biostate and AHF (High Purity)] in people with von Willebrand disorder. A randomised cross-over, multi-centre study. Thromb Haemost 2007;97:922-930

71. Perel JM, Just S, Rowell J, Williams B, Kennedy GA. Utility of the PFA-100 analyser in the evaluation of primary 
haemostasis in a paediatric population. Int J Lab Hematol 2007;29:480-481

72. Podda GM, Bucciarelli P, Lussana F, Lecchi A, Cattaneo M. Usefulness of PFA-100 testing in the diagnostic screening of patients with suspected abnormalities of hemostasis: comparison with the bleeding time. J Thromb Haemost 2007;5:2393-2398

73. Favaloro EJ, Patterson D, Denholm A, et al. Differential identification of a rare form of platelet-type (pseudo-) von Willebrand disease from type 2B VWD using a simplified ristocetin-induced-platelet-agglutination (RIPA) mixing assay and confirmed by genetic analysis. $\mathrm{Br} \mathrm{J}$ Haematol 2007;139:623-626

74. Karger R, Donner-Banzhoff N, Müller HH, Kretschmer V, Hunink M. Diagnostic performance of the platelet function analyzer (PFA-100) for the detection of disorders of primary haemostasis in patients with a bleeding history-a systematic review and meta-analysis. Platelets 2007;18:249-260

75. Giannini S, Mezzasoma AM, Leone M, Gresele P. Laboratory diagnosis and monitoring of desmopressin treatment of von Willebrand's disease by flow cytometry. Haematologica 2007;92:1647-1654

76. Favaloro EJ, Kershaw G, Bukuya M, Hertzberg M, Koutts J. Laboratory diagnosis of von Willebrand disorder (vWD) and monitoring of DDAVP therapy: efficacy of the PFA100 and vWF:CBA as combined diagnostic strategies. Haemophilia 2001;7:180-189

77. Franchini M, Gandini G, Manzato F, Lippi G. Evaluation of the PFA-100 system for monitoring desmopressin therapy in patients with type 1 von Willebrand's disease. Haematologica 2002;87:670

78. Koscielny J, von Tempelhoff GF, Ziemer S, et al. A practical concept for preoperative management of patients with impaired primary hemostasis. Clin Appl Thromb Hemost 2004;10:155-166

79. Franchini M, Zugni C, Veneri D, et al. High prevalence of acquired von Willebrand's syndrome in patients with thyroid diseases undergoing thyroid surgery. Haematologica 2004;89:1341-1346

80. Michiels JJ, Gadisseur A, van der Planken M, Schroyens W, van de Velden A, Berneman Z. Guidelines for the evaluation of intravenous desmopressin and von Willebrand factor/factor VIII concentrate in the treatment and prophylaxis of bleedings in von Willebrand disease types 1, 2, and 3. Semin Thromb Hemost 2006;32:636-645

81. Hanebutt FL, Rolf N, Loesel A, Kuhlisch E, Siegert G, Knoefler R. Evaluation of desmopressin effects on haemostasis in children with congenital bleeding disorders. Haemophilia 2008;14:524-530

82. Rose SS, Faiz A, Miller CH, Saidi P, Philipp CS. Laboratory response to intranasal desmopressin in women with menorrhagia and platelet dysfunction. Haemophilia 2008;14:571-578

83. van Vliet HHDM, Kappers-Klunne MC, Leebeek FWG et al. PFA-100 monitoring of von Willebrand factor (VWF) responses to DDAVP and FVIII/VWF concentrate substitution in von Willebrand disease type 1 and 2. Thromb Haemost 2008;100:462-468

84. Favaloro EJ. A better approach to monitoring of therapy in von Willebrand disease? Thromb Haemost 2008;100:371373

85. Cattaneo M, Lecchi A, Agati B, Lombardi R, Zighetti ML. Evaluation of platelet function with the PFA-100 system in patients with congenital defects of platelet secretion. Thromb Res 1999;96:213-217

86. Harrison C, Khair K, Baxter B, Russell-Eggitt I, Hann I, Liesner R. Hermansky-Pudlak syndrome: infrequent bleeding and first report of Turkish and Pakistani kindreds. Arch Dis Child 2002;86:297-301

87. Liang HP, Morel-Kopp MC, Curtin J, et al. Heterozygous loss of platelet glycoprotein (GP) Ib-V-IX variably affects platelet function in velocardiofacial syndrome (VCFS) patients. Thromb Haemost 2007;98:1298-1308

88. Giannini S, Mezzasoma AM, Guglielmini G, Rossi R, Falcinelli E, Gresele P. A new case of acquired Glanzmann's thrombasthenia: diagnostic value of flow cytometry. Cytometry B Clin Cytom 2008;74:194-199

89. Francis J, Francis D, Larson L, Helms E, Garcia M. Can the Platelet Function Analyzer (PFA)-100 test substitute for the template bleeding time in routine clinical practice? Platelets 1999;10:132-136

90. Wahba A, Sander S, Birnbaum DE. Are in-vitro platelet function tests useful in predicting blood loss following open heart surgery? Thorac Cardiovasc Surg 1998;46:228-231

91. Lasne D, Fiemeyer A, Chatellier G, Chammas C, Baron JF, Aiach M. A study of platelet functions with a new analyzer using high shear stress (PFA 100) in patients undergoing coronary artery bypass graft. Thromb Haemost 2000;84: 794-799

92. Forestier F, Coiffic A, Mouton C, Ekouevi D, Chêne G, Janvier G. Platelet function point-of-care tests in postbypass cardiac surgery: are they relevant? $\mathrm{Br} \mathrm{J}$ Anaesth 2002;89:715-721

93. Fattorutto M, Pradier O, Schmartz D, Ickx B, Barvais L. Does the platelet function analyser (PFA-100) predict blood loss after cardiopulmonary bypass? Br J Anaesth 2003;90: 692-693

94. Cammerer U, Dietrich W, Rampf T, Braun SL, Richter JA. The predictive value of modified computerized thromboelastography and platelet function analysis for postoperative blood loss in routine cardiac surgery. Anesth Analg 2003;96: 51-57

95. Avidan MS, Alcock EL, Da Fonseca J, et al. Comparison of structured use of routine laboratory tests or near-patient assessment with clinical judgement in the management of bleeding after cardiac surgery. Br J Anaesth 2004;92: 178-186

96. Hertfelder HJ, Bös M, Weber D, Winkler K, Hanfland P, Preusse CJ. Perioperative monitoring of primary and secondary hemostasis in coronary artery bypass grafting. Semin Thromb Hemost 2005;31:426-440

97. Madan M, Berkowitz SD, Christie DJ, et al. Rapid assessment of glycoprotein IIb/IIIa blockade with the platelet function analyzer (PFA-100) during percutaneous coronary intervention. Am Heart J 2001;141:226-233

98. Madan M, Berkowitz SD, Christie DJ, Smit AC, Sigmon $\mathrm{KN}$, Tcheng JE. Determination of platelet aggregation inhibition during percutaneous coronary intervention with the platelet function analyzer PFA-100. Am Heart J 2002; 144:151-158

99. Van der Planken MG, Claeys MJ, Vertessen FJ, et al. Comparison of turbidimetric aggregation and in vitro bleeding time (PFA-100) for monitoring the platelet inhibitory profile of antiplatelet agents in patients undergoing stent implantation. Thromb Res 2003;111: 159-164 
100. Konopka A, Spychalska J, Sitkiewicz D, et al. Expression of platelet surface receptors and early changes in platelet function in patients with STEMI treated with abciximab and clopidogrel versus clopidogrel alone. Am J Cardiovasc Drugs 2007;7:433-439

101. van Werkum JW, Gerritsen WB, Kelder JC, et al. Inhibition of platelet function by abciximab or high-dose tirofiban in patients with STEMI undergoing primary PCI: a randomised trial. Neth Heart J 2007;15:375-381

102. de Meijer A, Vollaard H, de Metz M, Verbruggen B, Thomas C, Novakova I. Meloxicam, $15 \mathrm{mg} /$ day, spares platelet function in healthy volunteers. Clin Pharmacol Ther 1999;66:425-430

103. van Kraaij DJ, Hovestad-Witterland AH, de Metz M, Vollaard EJ. A comparison of the effects of nabumetone vs meloxicam on serum thromboxane B2 and platelet function in healthy volunteers. Br J Clin Pharmacol 2002;53: 644-647

104. Fischetti D, Sciahbasi A, Leone AM, et al. Ticlopidine and aspirin fail to suppress the increased platelet aggregability that follows percutaneous coronary interventions. J Thromb Thrombolysis 2000;10:265-269

105. Fattorutto M. Measurement of the effect of ticlopidine with the platelet function analyser (PFA-100) during coronary stent implantation. Am Heart J 2003;146:E8

106. Hayward CP, Harrison P, Cattaneo M, Ortel TL, Rao AKThe Platelet Physiology Subcommittee of the Scientific and Standardization Committee of the International Society on Thrombosis and Haemostasis. Platelet function analyzer (PFA)-100 closure time in the evaluation of platelet disorders and platelet function. J Thromb Haemost 2006; 4:312-329

107. Reny JL, De Moerloose P, Dauzat M, Fontana P. Use of the PFA-100 closure time to predict cardiovascular events in aspirin-treated cardiovascular patients: a systematic review and meta-analysis. J Thromb Haemost 2008;6: 444-450

108. Snoep JD, Hovens MM, Eikenboom JC, et al. Association of laboratory-defined aspirin resistance with a higher risk of recurrent cardiovascular events: a systematic review and meta-analysis. Arch Intern Med 2007;167:1593-1599

109. Krasopoulos G, Brister SJ, Beattie WS, et al. Aspirin "resistance" and risk of cardiovascular morbidity: systematic review and meta-analysis. BMJ 2008;336:195-198

110. Reny JL, Quéré I, de Moerloose P, Fontana P. Aspirin response variability assessed with the PFA-100 device. Thromb Haemost 2008;99:968-969

111. Crescente M, Di Castelnuovo A, Iacoviello L, de Gaetano G, Cerletti C. Rebuttal to "Aspirin response variability assessed with the PFA-100 device" by Reny et al. Thromb Haemost 2008;99:969

112. Crescente M, Di Castelnuovo A, Iacoviello L, de Gaetano G, Cerletti C. PFA-100 closure time to predict cardiovascular events in aspirin-treated cardiovascular patients: a meta-analysis of 19 studies comprising 3,003 patients. Thromb Haemost 2008;99:1129-1131

113. Ziegler S, Maca T, Alt E, Speiser W, Schneider B, Minar E. Monitoring of antiplatelet therapy with the PFA-100 in peripheral angioplasty patients. Platelets 2002;13: 493-497

114. Grau AJ, Reiners S, Lichy C, Buggle F, Ruf A. Platelet function under aspirin, clopidogrel, and both after ischemic stroke: a case-crossover study. Stroke 2003;34:849-854
115. Mueller T, Haltmayer M, Poelz W, Haidinger D. Monitoring aspirin $100 \mathrm{mg}$ and clopidogrel $75 \mathrm{mg}$ therapy with the PFA-100 device in patients with peripheral arterial disease. Vasc Endovascular Surg 2003;37:117-123

116. Jilma B. Synergistic antiplatelet effects of clopidogrel and aspirin detected with the PFA-100 in stroke patients. Stroke 2003;34:849-854

117. Lepäntalo A, Virtanen KS, Heikkilä J, Wartiovaara U, Lassila R. Limited early antiplatelet effect of $300 \mathrm{mg}$ clopidogrel in patients with aspirin therapy undergoing percutaneous coronary interventions. Eur Heart J 2004; 25:476-483

118. Raman S, Jilma B. Time lag in platelet function inhibition by clopidogrel in stroke patients as measured by PFA- 100 . J Thromb Haemost 2004;2:2278-2279

119. Geiger J, Teichmann L, Grossmann R, et al. Monitoring of clopidogrel action: comparison of methods. Clin Chem 2005;51:957-965

120. Mani H, Linnemann B, Luxembourg B, Kirchmayr K, Lindhoff-Last E. Response to aspirin and clopidogrel monitored with different platelet function methods. Platelets 2006; 17:303-310

121. Agarwal S, Coakley M, Reddy K, Riddell A, Mallett S. Quantifying the effect of antiplatelet therapy: a comparison of the platelet function analyzer (PFA-100) and modified thromboelastography (mTEG) with light transmission platelet aggregometry. Anesthesiology 2006;105: 676-683

122. Alström U, Tydén H, Oldgren J, Siegbahn A, Ståhle E. The platelet inhibiting effect of a clopidogrel bolus dose in patients on long-term acetylsalicylic acid treatment. Thromb Res 2007;120:353-359

123. Serebruany VL, Malinin AI, Atar D. Combination antiplatelet therapy with aspirin and clopidogrel: the role of antecedent and concomitant doses of aspirin. An analysis of 711 patients. Cardiology 2007;107:307-312

124. Lev EI, Ramchandani M, Garg R, et al. Response to aspirin and clopidogrel in patients scheduled to undergo cardiovascular surgery. J Thromb Thrombolysis 2007;24:15-21

125. Malek LA, Grabowski M, Spiewak M, et al. Relation between impaired antiplatelet response to clopidogrel and possible pleiotropic effects. J Thromb Thrombolysis 2007;24: 301-305

126. Kotzailias N, Elwischger K, Sycha T, et al. Clopidogrelinduced platelet inhibition cannot be detected by the platelet function analyzer-100 system in stroke patients. J Stroke Cerebrovasc Dis 2007;16:199-202

127. Dyszkiewicz-Korpanty A, Olteanu H, Frenkel EP, Sarode R. Clopidogrel anti-platelet effect: an evaluation by optical aggregometry, impedance aggregometry, and the platelet function analyzer (PFA-100). Platelets 2007;18: 491-496

128. Konopka A, Spychalska J, Sitkiewicz D, et al. Expression of platelet surface receptors and early changes in platelet function in patients with STEMI treated with abciximab and clopidogrel versus clopidogrel alone. Am J Cardiovasc Drugs 2007;7:433-439

129. Serebruany VL, Malinin AI, Pokov A, Barsness G, Hanley DF. Effects of clopidogrel and aspirin in combination versus aspirin alone on platelet activation and major receptor expression in diabetic patients: the PLavix Use for Treatment Of Diabetes (PLUTO-Diabetes) trial. Am Heart J 2008;155:93.e1-97 
130. Fehr M, Galliard-Grigioni KS, Reinhart WH. Influence of acute alcohol exposure on hemorheological parameters and platelet function in vivo and in vitro. Clin Hemorheol Microcirc 2008;39:351-358

131. Pearson DA, Paglieroni TG, Rein D, et al. The effects of flavanol-rich cocoa and aspirin on ex vivo platelet function. Thromb Res 2002;106:191-197

132. Bordeaux B, Yanek LR, Moy TF, et al. Casual chocolate consumption and inhibition of platelet function. Prev Cardiol 2007;10:175-180

133. Scharbert G, Kalb ML, Duris M, Marschalek C, KozekLangenecker SA. Garlic at dietary doses does not impair platelet function. Anesth Analg 2007;105:1214-1218

134. Beckert BW, Concannon MJ, Henry SL, Smith DS, Puckett CL. The effect of herbal medicines on platelet function: an in vivo experiment and review of the literature. Plast Reconstr Surg 2007;120:2044-2050

135. Kwok Y, Ng KF, Li CC, Lam CC, Man RY. A prospective, randomized, double-blind, placebo-controlled study of the platelet and global hemostatic effects of Ganoderma lucidum (Ling-Zhi) in healthy volunteers. Anesth Analg 2005;101:423-426

136. Golański J, Muchova J, Golański R, Durackova Z, Markuszewski L, Watała C. Does pycnogenol intensify the efficacy of acetylsalicylic acid in the inhibition of platelet function? In vitro experience Postepy Hig Med Dosw (Online) 2006;60:316-321

137. Lippi G, Montagnana M, Franchini M, Favaloro EJ, Targher G. Dark chocolate: consumption for pleasure or therapy? J Thromb Thrombolysis 2008; Sept 23 [Epub ahead of print]

138. Kloner RA, Rezkalla SH. To drink or not to drink? That is the question Circulation 2007;116:1306-1317

139. Marietta M, Castelli I, Piccinini F, et al. The PFA-100 system for the assessment of platelet function in normotensive and hypertensive pregnancies. Clin Lab Haematol 2001;23:131-134

140. Vincelot A, Nathan N, Collet D, Mehaddi Y, Grandchamp $\mathrm{P}$, Julia A. Platelet function during pregnancy: an evaluation using the PFA-100 analyser. Br J Anaesth 2001; 87:890-893

141. Davies JR, Fernando R, Hallworth SP. Hemostatic function in healthy pregnant and preeclamptic women: an assessment using the platelet function analyzer (PFA-100) and thromboelastograph. Anesth Analg 2007;104:416-420

142. Nemmar A, Hoylaerts MF, Hoet PH, Vermylen J, Nemery B. Size effect of intratracheally instilled particles on pulmonary inflammation and vascular thrombosis. Toxicol Appl Pharmacol 2003;186:38-45

143. Nemmar A, Hoet PH, Dinsdale D, Vermylen J, Hoylaerts MF, Nemery B. Diesel exhaust particles in lung acutely enhance experimental peripheral thrombosis. Circulation 2003;107:1202-1208

144. Nemmar A, Nemery B, Hoet PH, Vermylen J, Hoylaerts MF. Pulmonary inflammation and thrombogenicity caused by diesel particles in hamsters: role of histamine. Am J Respir Crit Care Med 2003;168:1366-1372

145. Nemmar A, Hoylaerts MF, Hoet PH, Nemery B. Possible mechanisms of the cardiovascular effects of inhaled particles: systemic translocation and prothrombotic effects. Toxicol Lett 2004;149:243-253

146. Lippi G, Favaloro EJ, Franchini M, Guidi GC. Air pollution and coagulation testing: a new source of biological variability? Thromb Res 2008;123:50-54
147. Escolar G, Cases A, Vinas M, et al. Evaluation of acquired platelet dysfunctions in uremic and cirrhotic patients using the platelet function analyzer (PFA-100): influence of hematocrit elevation. Haematologica 1999;84: 614-619

148. Pihusch R, Rank A, Göhring P, Pihusch M, Hiller E, Beuers U. Platelet function rather than plasmatic coagulation explains hypercoagulable state in cholestatic liver disease. J Hepatol 2002;37:548-555

149. Bilgin AU, Karadogan I, Artac M, Kizilors A, Bligin R, Undar L. Hemodialysis shortens long in vitro closure times as measured by the PFA-100. Med Sci Monit 2007;13:CR141CR145

150. Frossard M, Fuchs I, Leitner JM, et al. Platelet function predicts myocardial damage in patients with acute myocardial infarction. Circulation 2004;110:1392-1397

151. Sestito A, Sgueglia GA, Spinelli A, et al. Increased platelet reactivity in unstable angina patients is not related to Creactive protein levels. Platelets 2006;17:336-339

152. Yee DL, Bergeron AL, Sun CW, Dong JF, Bray PF. Platelet hyperreactivity generalizes to multiple forms of stimulation. J Thromb Haemost 2006;4:2043-2050

153. Fuchs I, Frossard M, Spiel A, Riedmüller E, Laggner AN, Jilma B. Platelet function in patients with acute coronary syndrome (ACS) predicts recurrent ACS. J Thromb Haemost 2006;4:2547-2552

154. Giusti B, Gori AM, Marcucci R, et al. Role of glycoprotein Ia gene polymorphisms in determining platelet function in myocardial infarction patients undergoing percutaneous coronary intervention on dual antiplatelet treatment. Atherosclerosis 2008;196:341-348

155. Linden MD, Furman MI, Frelinger AL III, et al. Indices of platelet activation and the stability of coronary artery disease. J Thromb Haemost 2007;5:761-765

156. Serebruany VL, Malinin A, Ong S, Atar D. Patients with metabolic syndrome exhibit higher platelet activity than those with conventional risk factors for vascular disease. J Thromb Thrombolysis 2008;25:207-213

157. Jacopo G, Elisabetta V, Silverio S, et al. Identification of platelet hyper-reactivity measured with a portable device immediately after percutaneous coronary intervention predicts in stent thrombosis. Thromb Res 2007;121:407-412

158. Jilma-Stohlawetz P, Jilma B, Mannhalter C, et al. Platelet glycoprotein Ibalpha polymorphisms and function evaluated by the platelet function analyzer PFA-100 in patients with lupus anticoagulant: the association with thromboembolic disease. Ann Hematol 2007;86:719-725

159. Harrison P, Mackie I, Mathur A, et al. Platelet hyperfunction in acute coronary syndromes. Blood Coagul Fibrinolysis 2005;16:557-562

160. Franchini M, Lippi G. Von Willebrand factor and thrombosis. Ann Hematol 2006;85:415-423

161. Franchini M, Mannucci PM. Von Willebrand factor: another Janus-faced hemostasis protein. Semin Thromb Hemost 2008;34:663-669

162. Chakroun $\mathrm{T}$, Gerotziafas $\mathrm{G}$, Robert $\mathrm{F}$, et al. In vitro aspirin resistance detected by PFA-100 closure time: pivotal role of plasma von Willebrand factor. Br J Haematol 2004;124: 80-85

163. Kilanowska J, Favaloro EJ, Lippi G. Aspirin 'responsiveness,' 'non-responsiveness' or 'resistance': a putative role for von Willebrand factor? Blood Coagul Fibrinolysis 2008; 19:823-824 
164. Favaloro EJ. An update on the von Willebrand factor collagen binding (VWF:CB) assay: 21 years of age and beyond adolescence, but not yet a mature adult. Semin Thromb Hemost 2007;33:727-744

165. Favaloro EJ, Lippi G, Franchini M. Preface: laboratory diagnostics in thrombosis and hemostasis: the past, the present, and the future. Semin Thromb Hemost 2008;34: 579-584

166. Lippi G, Favaloro EJ. Activated partial thromboplastin time: new tricks for an old dogma. Semin Thromb Hemost 2008;34:604-611

167. Watson HG, Greaves M. Can we predict bleeding? Semin Thromb Hemost 2008;34:97-103

168. Chee YL, Crawford JC, Watson HG, Greaves M. Guidelines on the assessment of bleeding risk prior to surgery or invasive procedures. British Committee for Standards in Haematology. Br J Haematol 2008;140:496-504

169. Karon BS, Wockenfus A, Scott R, et al. Aspirin responsiveness in healthy volunteers measured with multiple assay platforms. Clin Chem 2008;54:1060-1065
170. Klein Gunnewiek JM, Hovestad-Witterland AH, Vollaard EJ, Fleuren HW, de Metz M. The influence of acetylsalicylic acid intake by healthy volunteers on duplicate PFA-100 measurements. Blood Coagul Fibrinolysis 2005; $16: 337-340$

171. Haubelt H, Anders C, Vogt A, Hoerdt P, Seyfert UT, Hellstern P. Variables influencing Platelet Function Analyzer-100 closure times in healthy individuals. $\mathrm{Br} \mathrm{J}$ Haematol 2005;130:759-767

172. Poulsen TS, Mickley H, Korsholm L, Licht PB, Haghfelt T, Jørgensen B. Using the Platelet Function Analyzer-100 for monitoring aspirin therapy. Thromb Res 2007;120: 161-172

173. Carcao MD, Blanchette VS, Stephens D, et al. Assessment of thrombocytopenic disorders using the Platelet Function Analyzer (PFA-100). Br J Haematol 2002;117: 961-964

174. Kretschmer V, Bade S, Weippert-Kretschmer M, Kratzer MA. Measurement of primary haemostasis using a pressure clamp technique. Platelets 2001;12:462-470 